Article

\title{
Multi-Objective Optimisation for Power System Planning Integrating Sustainability Indicators
}

\author{
Taimur Al Shidhani, Anastasia Ioannou and Gioia Falcone *D \\ School of Engineering, University of Glasgow, Glasgow G12 8QQ, UK; 2423358a@student.gla.ac.uk (T.A.S.); \\ anastasia.ioannou@glasgow.ac.uk (A.I.) \\ * Correspondence: gioia.falcone@glasgow.ac.uk; Tel.: +44-0141-330-3919
}

Received: 27 January 2020; Accepted: 29 April 2020; Published: 2 May 2020

\begin{abstract}
The increase in global electricity demand, along with its impact on climate change, call for integrating sustainability aspects in the power system expansion planning. Sustainable power generation planning needs to fulfill different, often contradictory, objectives. This paper proposes a multi-objective optimisation model integrating four objective functions, including minimisation of total discounted costs, carbon emissions, land use, and social opposition. Other factors addressed in the model include renewable energy share, jobs created, mortality rates, and energy diversity, among others. Single-objective linear optimisations are initially performed to investigate the impact of each objective function on the resulting power generation mix. Minimising land use and discounted total costs favoured fossil fuels technologies, as opposed to minimising carbon emissions, which resulted in increased renewable energy shares. Minimising social opposition also favoured renewable energy shares, except for hydropower and onshore wind technologies. Accordingly, to investigate the trade-offs among the objective functions, Pareto front candidates for each pair of objective functions were generated, indicating a strong correlation between the minimisation of carbon emissions and the social opposition. Limited trade-offs were also observed between the minimisation of costs and land use. Integrating the objective functions in the multi-objective model resulted in various non-dominated solutions. This tool aims to enable decision-makers identify the trade-offs when optimising the power system under different objectives and determine the most suitable electricity generation mix.
\end{abstract}

Keywords: multi-objective optimisation; genetic algorithm; electricity; sustainability; power system expansion planning; environmental; social; financial

\section{Introduction}

With increasing concerns regarding the impact of climate change, energy demand growth (electricity demand expanded by $4 \%$ in 2018 [1]), and resource depletion, careful consideration must be given to power expansion planning and the shift from fossil fuels to more sustainable resources [2]. International energy agreements and policies have driven this shift, including the Kyoto Protocol [3], Paris' Agreement [4], and the European Union 2030 Strategy [5].

Determining the optimal combination of power generation technologies at country level can be formulated as a mathematical programming problem, using the optimisation of a Key Performance Indicator (KPI) as the objective function, for example, the total power system cost [6-8] (including the investment cost of new generating technology, the fuel price, and the fixed and variable operating costs). Decision variables can be the types of energy production technologies, the location of installed technologies, and the installation time, among others. Sustainability is a key aspect in energy systems ensuring that environmental, social, and economic factors are taken into consideration in the solution. Certain relevant factors include energy security, reduction of negative environmental 
impacts (translated into carbon taxes and Greenhouse Gas (GHG) reduction targets) [9], number of jobs created [10], social opposition [11], and land use [12]. The consideration of the above factors shows that they often contradict each other [13,14]. Multi-objective Optimisation (MO) algorithms involve the simultaneous optimisation of more than one objective functions and are particularly useful for problems where trade-offs between two or more potentially conflicting objectives can be found [15].

Numerous authors in literature have investigated the integration of multiple factors within a $\mathrm{MO}$ framework to derive long-term optimum power generation mixes. In Reference [16], authors developed a mixed integer linear, two-stage multi-objective model to solve electricity-planning problems, minimising three objective functions: (i) cost, (ii) $\mathrm{CO}_{2}$, and (iii) $\mathrm{NO}_{\mathrm{x}}$ emissions. The electricity system expansion problem considered a planning horizon divided into three periods of five years each. The decision variables comprised the type of generation technologies, the location of installed technologies, and the installation time. Monte Carlo simulations were performed to derive various energy demand scenarios. The relationship between each pair of objective functions was investigated to understand the trade-offs during the optimisation process. Furthermore, authors adopted a weighted-sum approach, where the weight of the corresponding objective functions varied in 26 cases to produce a Pareto front. A Pareto front is a set of solutions in the decision variables space that are non-dominated with respect to each other. When moving from one Pareto solution to another, there is an amount of sacrifice in one objective(s), compensated by an amount of gain in the other(s). Pareto-optimal solution sets are usually preferred to single solutions as when considering real-life problems, the decision-maker's final solution is usually a trade-off. The size of Pareto-optimal sets can vary, but it typically increases with increasing number of objectives, due to the increasing weight combinations. A multi-objective interactive approach to identify the optimal generation mix in Andalucía, Spain was developed in Reference [17]. The MO was based on an interactive weighting of the objective functions by a factor, which can be re-evaluated, following an iterative process, until an optimum solution is reached. The paper addressed mainly environmental factors using the cost and vulnerability as objective functions, while other sustainability aspects, such as social indicators, were not considered. Another study has developed a combined simulation model [18]. Using Shanxi, China as a case study, a dual-objective optimisation problem was solved, with objective functions the amount of air pollutants and the net system costs. At district level, authors in Reference [19] developed a MO method for the district heating supply capacity and operation, including thermal storage, for a one-year time horizon. Three objective functions were considered: minimisation of the total discounted cost, carbon dioxide emissions, and exergy destruction. Authors in Reference [20] adopted a mixed integer linear programming model that involved the utilisation of both Multi-Objective Genetic Algorithm and Analytical Hierarchy Process (AHP). Three objective functions, namely minimum expansion costs, $\mathrm{CO}_{2}$ emissions and external costs were selected. This allowed the selection of the most suitable solutions from the Pareto front. Seven case studies, with different policies and technologies, were considered and the solution with the highest AHP score was selected. Relative weighting was assigned to each objective function, based on the decision-maker's preferences. While the paper addressed environmental costs, limited consideration was placed on social aspects. In Reference [21], authors constructed a long-term dual-stage MO approach to solve Croatia's energy expansion planning problem. The model focused on Renewable Energy (RE) technologies, along with the integration of electric vehicles. The model also involved meeting heating and cooling demand on top of electricity consumption. Three objective functions corresponding to minimising the net present value of the energy system, minimising net present value divided by the total energy generated and maximising RE penetration, resulted in the generation of a Pareto front. Trade-offs between these objective functions were analysed. Pareto-optimal solutions with high RE shares resulted in high installed capacities due to low load factors, and hence to significantly higher energy system costs. In Reference [22] optimised energy scenarios were designed for three time periods: 2020, 2030 and 2050, with respect to minimising annual cost and $\mathrm{CO}_{2}$ emissions. The paper has intuitively addressed the post-processing of Pareto fronts in energy $\mathrm{MO}$; however, it did not consider the social aspects of energy planning. In Reference [23], 
a Multi-Objective Evolutionary Algorithm (MOEA) coupled to EnergyPLAN (the EPLANopt model) was applied to South Tyrol's energy system. EPLANopt generated a set of Pareto-optimal solutions with objective functions the minimisation of: (i) total annual costs, (ii) $\mathrm{CO}_{2}$ emissions per person, and (iii) non-renewable contribution. The generated Pareto front demonstrated that at the same annual cost of the base case, it was possible to reduce $\mathrm{CO}_{2}$ emissions by $44 \%$, while annual costs could be maintained if investments in exports were redirected to energy efficiency renovations in buildings. Unlike the weighted-sum approach, this approach generates a set of Pareto-optimal solutions that are independent of subjective weighting or preferences. Another study [24] investigated energy expansion problems in Uganda by developing a MO model based on the epsilon-constrained method. Social and economic criteria were incorporated by means of three objective functions: minimum total discounted costs, minimum urban versus rural electrification inequality, and minimum regional electrification inequality. More environmental factors were included by means of constraints. As a result, a three-dimensional Pareto front for the Ugandan nation was generated, which indicated that inequalities can be completely diminished at the expense of a slightly higher discounted cost. Moreover, based on the results obtained from the model, the paper concluded that the current expansion plans, which include nuclear power plants, are infeasible and off-grid electrification using concentrated solar power plants would be preferred.

Different MO algorithms have been deployed to solve energy system planning problems, such as $\varepsilon$-constraint $[24,25]$ and multi-objective genetic algorithms (e.g., Non-dominated Sorted Genetic Algorithm-II (NSGA-II) [26-29], NSGA-III [30,31], and the Particle Swarm Optimisation (PSO) approach [32,33]). Genetic Algorithms (GA) comprise popular meta-heuristic optimisation methods particularly well-suited for problems with multiple-objectives. Compared to other optimisation methods, GA are appropriate to solve practical optimisation problems, as they can efficiently handle discontinuous objective functions without not relying on initial solution guesses [34]. A literature review of genetic algorithms (including Multi-objective Genetic Algorithm (MOGA), Weight-based Genetic Algorithm (WBGA), Pareto-Archived Evolution Strategy (PAES), etc.) was carried out in Reference [35], noting that key differentiators among multi-objective GA focus on the fitness assignment process, elitism, or diversification approaches. In Reference [29], authors employed a variant of NSGA-II to optimise the design parameters of an underwater compressed air energy storage system. The NSGA-II method was also employed in Reference [27] to optimise the sizing of a multi-source photovoltaic (PV)/Wind with Hybrid energy storage system, while, in Reference [28], the same method is used to identify the optimal location and capacity of distributed energy storage systems (DESSs). While MO problems on power expansion planning have been well documented, fewer papers have utilised evolutionary algorithms in multi-stage problems. In fact, most of the long-term expansion problems adopt weighted-sum approaches, which usually require either applying arbitrary weights to individual objective functions or having objective functions in a percentage form.

This paper proposes a multi-objective multi-period optimisation model, which derives the optimum power generation expansion mix of a country integrating sustainability indicators. Numerous other factors are addressed in the model, including RE share, jobs created, mortality rates, and energy diversity. Subsequently, the model is applied to Indonesia's power system for the period 2016-2030 to indicate the applicability of the method. The proposed model uses a controlled elitist genetic algorithm, which is a variant of the widely used NSGA-II [36]. As such, novelty of the present work lies on the combination of sustainability aspects within a MO framework, in order to explore potential conflicts and trade-offs among these aspects in terms of technology utilisation.

The rest of the paper is organised as follows: Section 2 provides an overview of literature on sustainability indicators for power generation technologies/systems, while Section 3 describes the current optimisation problem, along with its mathematical formulation. Section 4 outlines the generic process of the multi-objective genetic algorithm optimization, as well as the NSGA-II process. Accordingly, Section 5 introduces the case study characteristics and the input data of the model. 
Section 6 discusses the key results of the single-and multi-objective optimisation problems, while Section 7 draws the main conclusions of this work.

\section{Overview of Sustainability Indicators in Energy Systems}

The optimisation of the electricity mix of a country requires adopting a whole systems, multi-disciplinary approach accounting for a number of social, economic, environmental, and technological indicators. Several papers focusing on the assessment of energy technologies were reviewed to identify appropriate sustainability indicators for this study.

A multi-criteria analysis was performed in Reference [37] to assess the sustainability of selected technologies (hydrogen fuel cells, hydro, wind, solar, geothermal, coal, natural gas, and nuclear power plant). Land use, social effects, unit energy costs, and $\mathrm{CO}_{2}$ emissions were among the criteria considered to assess the alternative technologies. In Reference [38], authors reviewed a set of energy performance and environmental indicators for renewable energy systems coupled with battery solutions. Relevant energy performance indicators included embodied energy, gross primary energy requirement, and net delivered electricity, among others, while environmental KPIs included life-cycle $\mathrm{CO}_{2}$ emissions, global warming potential, reduction of the direct $\mathrm{CO}_{2}$ emissions, avoided $\mathrm{CO}_{2}$ emissions, and $\mathrm{CO}_{2, \text { eq }}$ payback time. In Reference [39], sustainability indicators for energy production projects were categorised under physical, economic, social, and environmental categories. Social indicators included jobs creation, human health impact, safety risks, and social acceptability, while relevant environmental indicators were GHG emissions, land-use, and resources sustainability. The paper also presents the mathematical formulation of these indicators. Authors in Reference [40] rank a set of selected technologies under six different scenarios through an AHP, integrating technical (energy efficiency, resource potential, water consumption, etc.), economic (CAPEX, OPEX, and cost of electricity), environmental $\left(\mathrm{CO}_{2}\right.$ emissions, $\mathrm{NO}_{\mathrm{x}}$ emissions, $\mathrm{SO}_{2}$ emissions), and social criteria (jobs creation, safety risks, social acceptability).

Authors in Reference [41] addressed the issue of subjective indicators by adopting multi-objective grey linear programming. This involved assigning subjective indicators to linguistic terms, which were subsequently used to evaluate the ranking of different energy technologies. While this method has reported satisfactory results, implementing this approach would not be suitable in case additional objective functions were to be added, as this would create an additional degree of complexity. On the other hand, in Reference [40], the importance of social and environmental criteria is highlighted in the assessment of energy technologies in Egypt. Each energy technology was assessed against several indicators using multi-criteria decision analysis (MCDM). The values of qualitative indicators, such as social acceptability, was determined using online surveys. Sustainability indices were assigned values per technology based on a Likert scale of 1-5. In Reference [10], authors assessed sustainability and resilience criteria based on an ordinal scale, while technology ratings were collected from a survey. In a different study [42], authors further built up on the findings of the former paper by investigating each criterion into greater detail collecting inputs from European Experts.

\section{Multi-Objective Genetic Algorithm Optimisation}

\subsection{Multi-Objective Genetic Algorithm Process}

Multi-objective Optimisation (MO) problems typically include the minimisation/maximisation of a number of objective functions while satisfying a number of constraints. The problem can be generically formulated as follows [34]:

Minimise or Maximise

Subject to

$$
\begin{array}{cl}
f_{m}(x), & \mathrm{m}=1,2, \ldots, \mathrm{M} \\
g_{j}(x) \geq 0, & \mathrm{j}=1,2, \ldots, \mathrm{J} \\
h_{k}(\boldsymbol{x})=0, & \mathrm{k}=1,2, \ldots, \mathrm{K} \\
x_{i}^{(L)} \leq x_{i} \leq x_{i}^{(U)} & \mathrm{l}=1,2, \ldots, \mathrm{n},
\end{array}
$$

where $\mathbf{x} \in R^{n}$ is a vector of $n$ decision variables $\mathbf{x}=\left(x_{1}, x_{2}, \ldots, x_{n}\right)^{T}$. The solutions satisfying the constraints comprise the feasible decision variable space $S \subset R^{n}$. In MO problems, the objective 
functions constitute a multidimensional space, called objective space, $Z \subset R^{M}$, in addition to the usual decision variable space. For each solution, $\mathbf{x}$ in the decision variable space, a point $z \in R^{M}$ in the objective space exists. The sorting process leads to the identification of the non-dominated solutions, which are also called Pareto-optimal solutions (POS) [34]. To identify the POS of a multi-objective genetic algorithm, the process of natural selection applies.

Genetic Algorithms (GA) are metaheuristic search techniques inspired by the theory of natural evolution, reflecting the process of natural selection, where the fittest individuals are selected for reproduction and generation of next generation's off springs [29]. GA are able to simultaneously search different regions of a solution space, enabling the exploration of a diverse set of solutions for problems with non-convex, discontinuous, and multi-modal solutions spaces [35]. The crossover operator exploits solutions with high fitness scores to create new solutions from other unexplored parts of the Pareto front. The design vector created from the decision variables and their respective imposed boundaries is stochastic, as the values of the decision solutions are randomly assigned [29]. GA starts with the generation of an initial population, which then undergoes the evaluation stage with respect to the objective functions to calculate the individual's fitness value. Accordingly, a sorting (selection) process of the solutions is carried out, according to which, a pair of solutions are chosen and compared against each other to test if the following conditions are true:

1. The solution $\mathbf{x}_{1}$ is no worse than the solution $\mathbf{x}_{2}$ in all objectives. The solutions are compared based on their fitness values with respect to the objective functions.

2. The solution $\mathbf{x}_{1}$ is strictly better than $\mathbf{x}_{2}$ in at least one objective.

If both conditions are true, the first solution dominates the second solution. Accordingly, the sorting process evaluates all solutions to determine those that are non-dominated. Termination conditions include limits on fitness, time, generations, and function tolerance and determine the termination of the iterations. If the termination criteria are not reached, the genetic algorithm proceeds to generate an offspring population from the selected population set. Otherwise, the optimisation returns the non-dominated solutions (Pareto-optimal). GA uses two operators to generate the offspring population: the crossover and the mutation. The crossover involves the combination of two chromosomes (parents) to form a new chromosome (offspring). The parents come from the pool of selected solutions with high fitness values, so that genes of good chromosomes are inherited to the offspring, leading to the convergence to an overall good solution. Mutation includes random changes into the genes of the chromosomes with the aim to reintroduce genetic diversity to the population and facilitate the search escape from local optima. Reproduction comprises the selection of the best solutions for the next generation, based on the selection process previously described, through the assignment of fitness values.

\subsection{Non-Dominated Sorting Genetic Algorithm II (NSGA-II)}

NSGA-II [36] is an elitist GA, which favours solutions with better fitness value, while its controlled version also favours solutions, which can facilitate the diversity of the population even with lower fitness values. Diversity of population, which is achieved through controlling the elite members of the population (elitism), is important to be maintained to allow convergence to an optimal Pareto front. The algorithm applies two metrics, the non-dominated sorting and the crowding distance sorting to each individual of the current population. Two random individuals compete in a tournament in terms of the two metrics and the winner proceeds to the next selection stage.

The NSGA-II process is illustrated in Figure 1. The algorithm uses a fixed population size of N. In generation $t$, the offspring population $Q_{t}$ of size $N$ is generated from the parent population $P_{t}$ and are combined together to form a new population $\left(R_{t}=P_{t} \cup Q_{t}\right)$ of $2 N$ size. Subsequently, through the sorting process, the population $R_{t}$ is classified into the different non-domination classes and the new population is filled by points of different non-domination fronts. The filling begins with the first class non-dominated front, then the second, and so on. Considering the size of the population is $2 \mathrm{~N}$, not all 
fronts can cover the $\mathrm{N}$ slots available for the next parent population. At the last front, where there might be more points than the remaining slots in the new population $P_{t+1}$, the algorithm selects the points that will increase the diversity of the population. The sorting of the last front is based on the calculation of the crowding distance values of the remaining points and their listing in descending order; points from the top of this list are chosen to be included in the next generation $\mathrm{P}_{\mathrm{t}+1}$. More details on the NSGA-II process can be found in Reference [43].

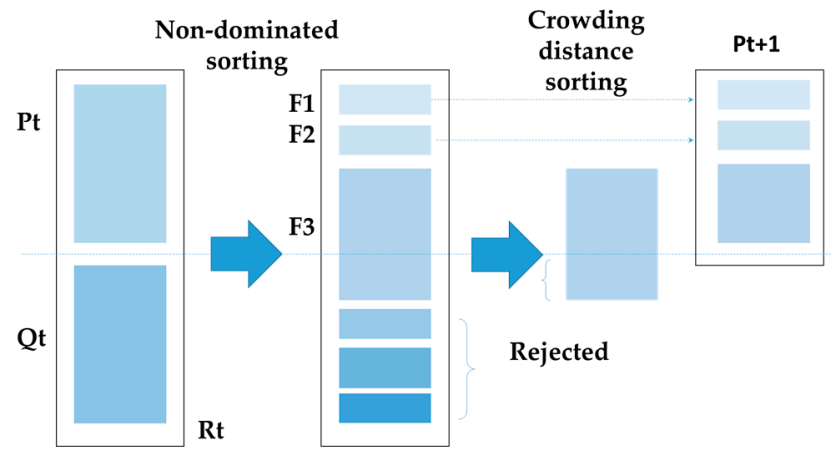

Figure 1. Non-dominated Sorted Genetic Algorithm (NSGA) process (based on Reference [43]).

\section{Optimisation Model}

\subsection{Problem Statement}

This study investigates the impact of sustainability factors towards defining optimal power generation mixes in medium-to-long-term national or regional energy expansion planning. These factors include carbon emissions, land use, social opposition, jobs creation, mortality rates, renewable contribution, import dependency, and technology diversity. Long-term energy planning normally involves determining the financially optimal power generation combination from a wide range of energy technologies and sources. The optimal combination of these technologies is managed in a manner that will satisfy future demand growth, as well as compensate for decommissioned power plants.

The planning horizon corresponds to fifteen years, divided into three periods. The technologies considered include pulverised coal fired units (PCF), natural gas combined cycle (NGCC), diesel engine (DE), hydro, geothermal power stations, biomass, onshore and offshore wind, solar photovoltaic (PV), and concentrated solar thermal (CSP) power plants.

\subsection{Nomenclature}

All the parameters and variables used in the model are summarised in Tables 1 and 2, respectively.

Table 1. List of input parameters along with their definitions.

\begin{tabular}{ccc}
\hline Parameters & Definition & Units \\
\hline $\mathrm{Capex}_{\tau}$ & Capital costs per installed capacity of technology, $\tau$ & $\$ / \mathrm{kW}$ \\
$\mathrm{Cfixed}_{\tau}$ & Fixed costs per installed capacity of technology, $\tau$ & $\$ / \mathrm{kW}-$ year \\
$\mathrm{Cfuel}_{\tau}$ & Fuel costs per output generated of technology, $\tau$ & $\$ / \mathrm{MWh}$ \\
$\mathrm{Ctax}_{\mathrm{t}}$ & Carbon tax imposed at each time interval & $\$ / \mathrm{tnCO} 2$ \\
$\mathrm{CVAR}_{\tau}$ & Variable costs per output generated of technology, $\tau$ & $\$ / \mathrm{MWh}$ \\
$\mathrm{CF}_{\tau}$ & Capacity factor of technology, $\tau$ & $\%$ \\
$\mathrm{CL}_{\tau}$ & Maximum construction limit of technology, $\tau$ & $\mathrm{MW}$ \\
$\mathrm{CO}_{2}$ rate $_{\tau}$ & Carbon intensity of technology, $\tau$ & $\mathrm{tn} / \mathrm{MWh}$ \\
$\mathrm{CO}_{2}$ target $_{\mathrm{t}}$ & Total carbon emissions limit at period, $\mathrm{t}$ & tonnes \\
$\mathrm{CONlimit}_{\tau, \mathrm{t}}$ & Construction limit at period, t for technology, $\tau$ & $\mathrm{MW}$ \\
$\mathrm{EPotcap}_{\tau}$ & Energy potential of renewable technology, $\tau$ & $\mathrm{MW}$ \\
$\mathrm{IDR}_{\mathrm{t}}$ & Import dependency ratio & - \\
$\mathrm{JC}_{\tau}$ & Potential jobs created per installed capacity of technology, t & $\mathrm{Jobs} / \mathrm{MWa}$ \\
$\mathrm{L}_{\tau}$ & Electrical transmission losses & $\%$ \\
\hline
\end{tabular}


Table 1. Cont.

\begin{tabular}{ccc}
\hline Parameters & Definition & Units \\
\hline $\mathrm{LT}_{\tau}$ & Lifetime of the plant of technology, $\tau$ & years \\
$\mathrm{LU}_{\tau}$ & Characteristic land used per electricity generated of technology, $\tau$ & $\mathrm{m}^{2} / \mathrm{MWh}$ \\
$\mathrm{LUtarget}_{\mathrm{t}}$ & Total land used limit at period, $\mathrm{t}$ & $\mathrm{m}^{2}$ \\
$\mathrm{MR}_{\tau}$ & Characteristic potential mortality rates per electricity generated from & Deaths $/ \mathrm{PWh}$ \\
$\mathrm{Maxprop}_{\tau, \mathrm{t}}$ & technology, $\tau$ & $\%$ \\
$\mathrm{Minprop}_{\tau, \mathrm{t}}$ & Maximum contribution cap of technology, $\tau$ & $\%$ \\
$\mathrm{O}_{\tau}$ & Minimum contribution cap of technology, $\tau$ & $\%$ \\
$\mathrm{OP}$ & Own electricity consumption of technology, $\tau$ & hours $/$ year \\
$\mathrm{r}$ & Maximum annual operating hours $(8760)$ & $\%$ \\
$\mathrm{Rmargin}_{\mathrm{Rtech}}$ & Interest and discount rate & $\%$ \\
$\mathrm{REtarget}_{\mathrm{t}}$ & Reserve Margin & - \\
$\mathrm{SOtarget}_{\mathrm{t}}$ & Experts' rating of technology, $\tau$ & $\%$ \\
$\mathrm{SO}_{\tau}$ & Renewable energy contribution target & $\%$ \\
$\mathrm{t}$ & Overall social opposition limit at period, $\mathrm{t}$ & $\%$ \\
$\tau$ & Social opposition for technology, $\tau$ & \\
$\tau$ & Set of periods within the planning horizon & \\
& Set of power generation plants: coal: 1, natural gas: 2, oil: 3, hydro: 4, & \\
\hline
\end{tabular}

Table 2. Definition of variables.

\begin{tabular}{|c|c|c|}
\hline Variables & Definition & Units \\
\hline $\mathrm{ACP}_{\mathrm{t}}$ & Total installed capital costs at period, $\mathrm{t}$ & $\$$ \\
\hline $\mathrm{CD}_{\mathrm{t}}$ & Power consumption at period, $\mathrm{t}$ & MWh \\
\hline CAPEX $_{t}$ & Total capital costs at period, $\mathrm{t}$ & $\$$ \\
\hline Carboncost $t_{t}$ & Total carbon costs at period, $\mathrm{t}$ & $\$$ \\
\hline $\mathrm{CO}_{2}$ emitted $_{\mathrm{t}}$ & Total carbon emissions produced at period, $\mathrm{t}$ & $\operatorname{tnCO}_{2}$ \\
\hline $\mathrm{DIC}_{\tau, \mathrm{t}}$ & Installed capacities that will be decommissioned at period, $\mathrm{t}$ for technology, $\tau$ & MW \\
\hline $\mathrm{EIC}_{\tau, \mathrm{t}}$ & Existing installed capacities at period, $\mathrm{t}$ for technology, $\tau$ & MW \\
\hline FIXEDcost $t_{t}$ & Total fixed costs at period, $\mathrm{t}$ & $\$$ \\
\hline Fuelcost $_{t}$ & Total fuel costs at period, $\mathrm{t}$ & $\$$ \\
\hline IMPnet & Imported energy resource & MW \\
\hline Jobs $_{\mathrm{t}}$ & Total number of jobs created at period, $\mathrm{t}$ due to newly installed technologies & No of Jobs \\
\hline Landused $_{t}$ & Total land used at period, t either from newly installed or existing technologies & $\mathrm{m}^{2}$ \\
\hline Mortality $_{+}$ & Overall potential mortality rate of the power generation mix at period, $t$ & No of deaths \\
\hline $\mathrm{NIC}_{\tau, \mathrm{t}}$ & Newly installed capacities at period, t of technology, $\tau$ (decision variables) & MW \\
\hline Pgen $_{\tau, \mathrm{t}}$ & Total power generated at period, $\mathrm{t}$ from technology, $\tau$ & MWh \\
\hline $\mathrm{PD}_{\mathrm{t}}^{2, \mathrm{l}}$ & Peak demand at period, $\mathrm{t}$ & MW \\
\hline $\mathrm{RIC}_{\tau, \mathrm{t}}$ & Required installed capacities at period, $t$ from technology, $\tau$ & MW \\
\hline SocialOpposition $_{\mathrm{t}}$ & Total social opposition for the electricity mix at period, $t$ & $\%$ \\
\hline Supply & Country's own supply of energy resource & MW \\
\hline $\mathrm{TDC}_{\mathrm{t}}$ & Total discounted costs at period, $\mathrm{t}$ & $\$$ \\
\hline $\mathrm{TLU}_{\mathrm{t}}$ & Total land used by power generation technologies at period, $t$ & $\mathrm{~m}^{2}$ \\
\hline TotalCost $t_{t}$ & Sum of all individual costs at period, $\mathrm{t}$ & $\$$ \\
\hline TSO & Total social opposition of the power generation mix & $\%$ \\
\hline VARcost $t_{t}$ & Total variable costs at period, $\mathrm{t}$ & $\$$ \\
\hline $\mathrm{x}_{\tau}$ & Fractional contribution of technology, $\tau$ to the power generation mix & - \\
\hline
\end{tabular}

\subsection{Model Structure}

An overview of the proposed model is shown in Figure 2. RE penetration targets, technology diversity and energy security were among the constraints taken into consideration. Maximising RE penetration was not incorporated as an objective function, since high portions of solar and wind power plants could lead to intermittency issues. Nevertheless, energy storage technologies could also be incorporated to the model in the future to tackle such issues. Furthermore, environmental indicators, such as carbon emissions and land use, are incorporated as objective functions, in addition to social opposition and total discounted costs. The decision variables of the optimisation model comprise the new installed capacities at each period for each technology, $\mathrm{NIC}_{\tau, \mathrm{t}}$. 


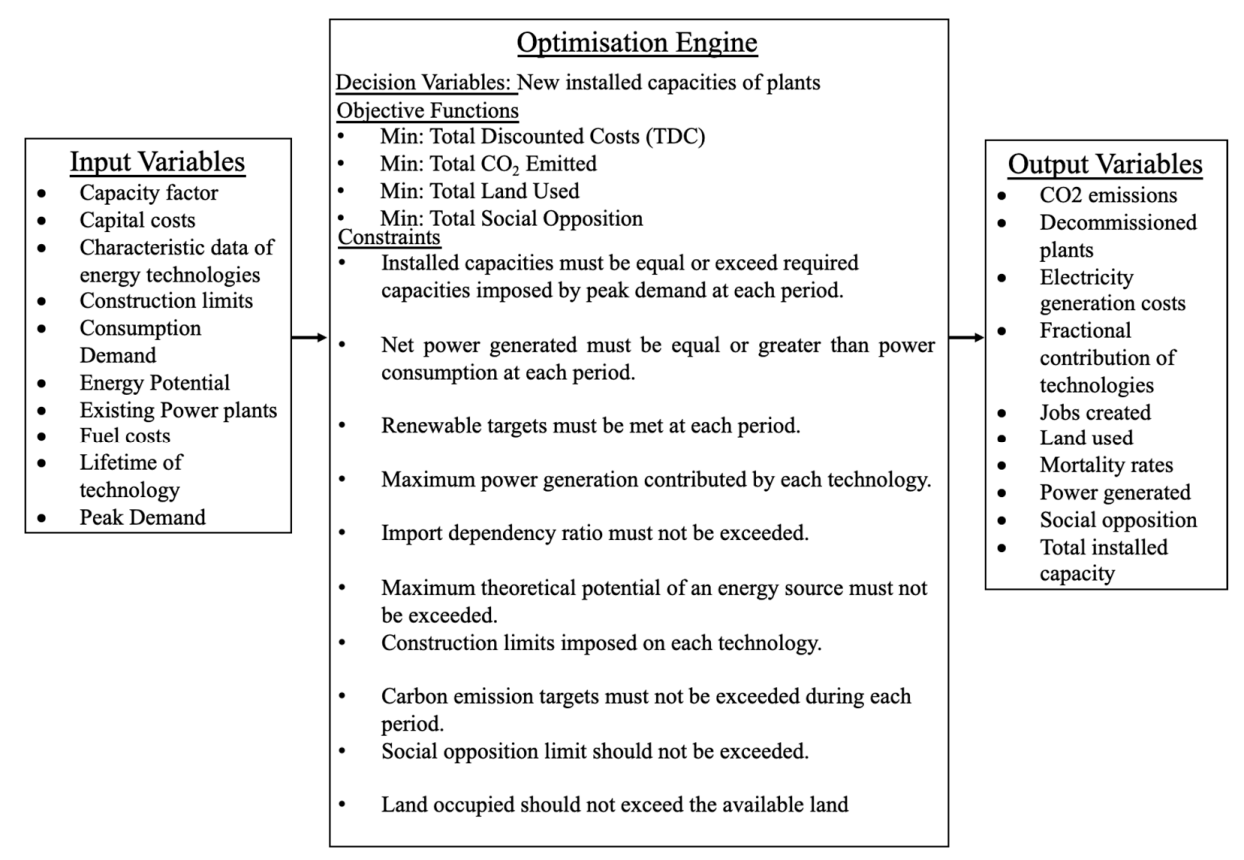

Figure 2. Summarised structure of the developed model.

The model was developed in MATLAB, employing the controlled NSGA-II procedure for the first two periods and linear constrained single-objective optimisation for the final period. The evolutionary multi-objective algorithm allowed the integration of selected objective functions, generating a series of Pareto-optimal solutions. For each period, these solutions are generated via an internal iteration process described in Section 3. The Pareto-optimal solutions (representing the new installed capacities) resulting from the first MO were introduced as inputs in the next period, as demonstrated in Figure 3. As such, the number of solutions derived from each optimisation have a considerable impact on the total computational time of the model.

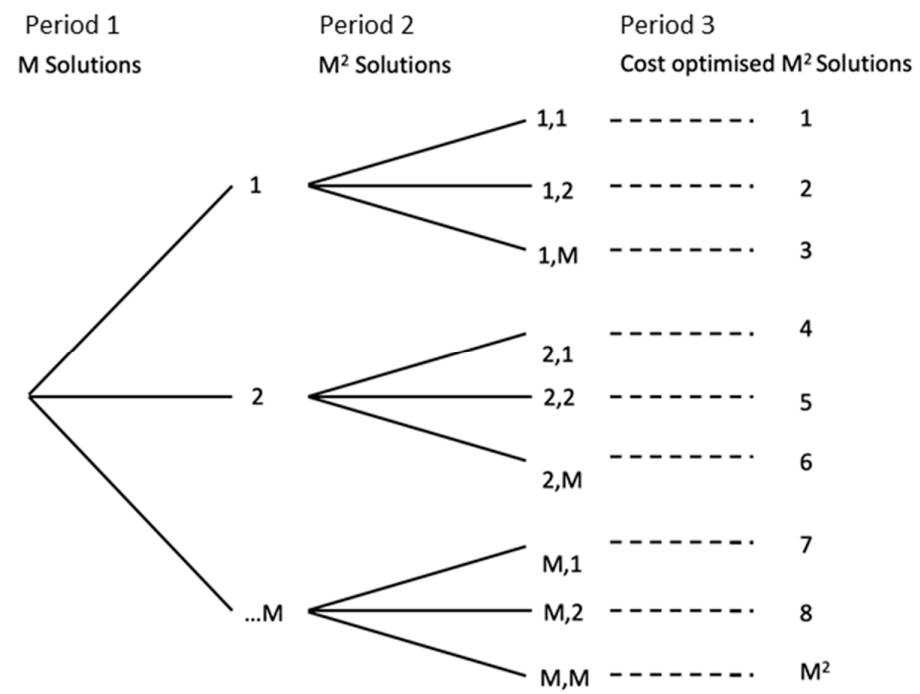

Figure 3. Optimisation approach of the model.

In general, an initial random population of 200 is recommended when the number of design variables is higher than 5 , while, for less than 5 , the initial population is set to 50 . In this problem, MATLAB's controlled elitistic genetic algorithm (a variant of NSGA-II) has been applied, which uses the Pareto fraction and the distance function to control elitism. The Pareto fraction determines the 
fraction of individuals (elite members) to keep on the Pareto front, while the distance function maintains diversity to the front by including individuals relatively distant from the front [44]. To identify the appropriate number of initial population and Pareto fraction, a sensitivity analysis was carried out to test the impact of different values on the performance of the algorithm, and the resulting Pareto fronts were plotted in Figure 4 for comparison. In general, as illustrated in Figure 4, increasing the value of the Pareto fraction results in non-dominated solutions closer to the bottom left of the plot, corresponding to better solutions for the minimisation problem. For example, the Pareto fraction $=0.45$ (blue colour) achieves better overall proximity in its solution set (meaning that solutions offer better objective values) than the Pareto fraction $=0.25$ (red colour). In this paper, a Pareto fraction of 0.35 was deemed a good compromise of computational time versus performance of the $\mathrm{MO}$ algorithm.

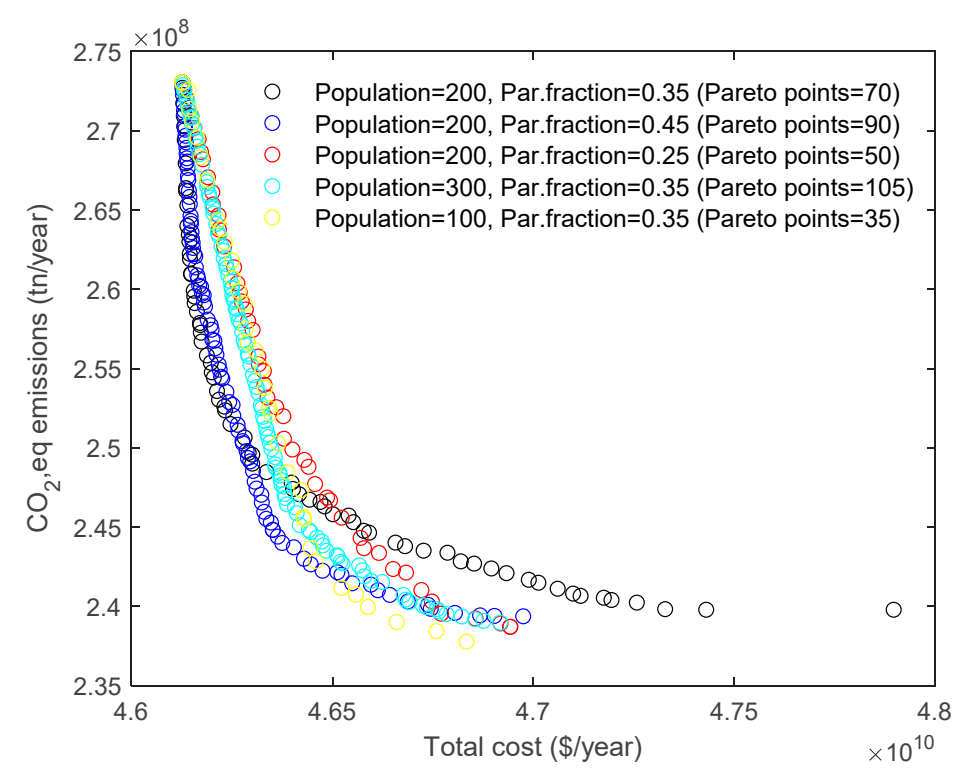

Figure 4. Pareto fronts for varying initial population and Pareto fraction inputs.

The optimisation process, therefore, produced a set of 70 non-dominated solutions in period 1. Each of the 70 solutions generated in the former period underwent a second MO process, generating another 70 solutions in period two, leading to a total of $70 \times 70=4900$ non-dominated solutions in the second period, which were, subsequently, optimised through a single-objective optimisation in the final period, resulting in 4900 total solutions. Using the $\mathrm{MO}$ in the final period would require intensive computing power $(70 \times 4900=343,000$ solutions). Instead, a single-objective optimisation (setting the remaining objective functions as constraints considering the results of the first and second periods) can lead to satisfactory results. The minimisation of the discounted total cost was selected as the single objective function with the imposition of a carbon tax amounting to $30 \$ / \mathrm{tn}$, in the final period. Applying a single objective optimisation at the last period, apart from reducing the dimensionality of the problem, it enables the decision-maker to set a priority objective and obtain the desired solution at a specific point in time. This method can be generalised to implement MOs with varying objective functions through the different periods of the power systems expansion planning, according to the foreseen priorities of the stakeholders at each respective period.

\subsection{Assumptions}

A number of reasonable assumptions were made to formulate the optimisation problem:

1. The quantification of solar PV degradation rate is of paramount importance to stakeholders. This is because it represents the actual decrease in PV power production, thus directly affecting future cash flows. The degradation rate varies according to the technology, while certain technologies' degradation rate is also affected by the ambient temperature. For example, thin-film technology 
has a mean degradation rate of almost 1.4\%/year, while the degradation rate of $\mathrm{x}$-Si technologies is in the range of $0.8-0.9 \% /$ year [45]. Considering that higher degradation rates are expected in hotter climates (Indonesia's annual average high temperature is $31^{\circ} \mathrm{C}$ and low temperature $26.3{ }^{\circ} \mathrm{C}$ [46]), an annual degradation of $1 \%$ was assumed a meaningful assumption. In the developed model, solar PV panels were estimated to degrade at a constant rate of $1 \%$ annually throughout their lifetime [45,47].

2. The projected increase in electricity demand for the applied case study is estimated to correspond to $5 \%$ annually [48].

3. Electricity-generating technologies, apart from PCF, NGCC, and DE, produce zero carbon emissions, as only the operational emissions were considered in this model, instead of their non-zero lifecycle emissions [49].

4. Capital costs of solar and wind technologies are estimated to decrease due to technological advancements and learning effects at a constant rate of $3 \%$ and $1.5 \%$ per year, respectively, throughout the optimisation periods [50].

5. Despite the historical volatility of fuel prices for PCF, NGCC, and DE, they were assumed constant, as this study does not focus on modelling uncertainty. Nevertheless, normally high, medium and low cases are often generated to examine the degree of impact fuel prices have on the expansion planning [8]. This can be considered as future work for the model that was developed.

6. The total costs were discounted at an assumed discount rate $r$ of $4 \%$ [51]. The International Energy Agency recommends an electricity supply reserve margin in the range of 20-35\% [52]. Therefore, the reserve margin that was applied in this model corresponded to $35 \%$. Furthermore, a plant's own use and transmission losses were assumed at 5 and $8 \%$, respectively [53].

\subsection{Objective Functions}

\subsubsection{Minimising Discounted Total Costs}

The total electricity generation cost of a power plant consists of several costs presented here. These equations refer to the existing power plants during a given period before the optimisation of the next period. The capital expenditure of power plants was multiplied by an annualization factor $\left(\frac{\mathrm{r}}{1-(1+\mathrm{r})^{-\mathrm{LT} \tau}}\right)$ dividing the investment cost into yearly instalments throughout the lifetime of the power plant. This factor assumes that the costs are borrowed as an initial investment and thus must be paid back with an interest rate, $r$.

$$
\mathrm{EACP}_{\mathrm{t}}=\sum_{\tau=1}^{10}\left(\mathrm{EIC}_{\tau, \mathrm{t}} \cdot \operatorname{Capex}_{\tau}\right) \cdot\left(\frac{\mathrm{r}}{1-(1+\mathrm{r})^{-\mathrm{LT} \tau}}\right) \quad \forall \mathrm{t} 1: 3
$$

Furthermore, the fixed cost of a plant EFIXEDcost $t_{t}$ is independent of the output and was calculated using the following equation.

$$
\text { EFIXEDcost }_{t}=\sum_{\tau=1}^{10}\left(\text { EIC }_{\tau, t} \cdot \text { Cfixed }_{\tau}\right) \quad \forall \mathrm{t} 1: 3
$$

On the other hand, the variable costs $\left(\right.$ VARcost $\left._{t}\right)$, fuel costs $\left(\right.$ EFuelcost $\left._{t}\right)$, and carbon costs (ECarboncost $t_{t}$ ) depend on the electricity generated by the power plant. Therefore, to obtain an annual value, they must be multiplied by the product of the technology's capacity factor $\mathrm{CF}_{\tau}$ and maximum annual operating hours (OP). The carbon cost is only non-zero when a carbon tax $\mathrm{Ctax}_{t}$ is imposed.

$$
\text { EVARcost }_{\mathrm{t}}=\sum_{\tau=1}^{10}\left(\mathrm{EIC}_{\tau, \mathrm{t}} \cdot \mathrm{CF}_{\tau} \cdot \mathrm{OP} \cdot \mathrm{CVAR}_{\tau}\right) \quad \forall \mathrm{t} 1: 3
$$




$$
\begin{gathered}
\text { EFuelcost }_{\mathrm{t}}=\sum_{\tau=1}^{10}\left(\mathrm{EIC}_{\tau, \mathrm{t}} \cdot \mathrm{CF}_{\tau} \cdot \mathrm{OP} \cdot \mathrm{Cfuel}_{\tau}\right) \quad \forall \mathrm{t} 1: 3, \\
\text { ECarboncost }_{\mathrm{t}}=\sum_{\tau=1}^{10}\left(\mathrm{EIC}_{\tau, \mathrm{t}} \cdot \mathrm{CF}_{\tau} \cdot \mathrm{OP} \cdot \mathrm{Ctax}_{\mathrm{t}} \cdot \mathrm{CO}_{2} \text { rate }_{\tau}\right) \quad \forall \mathrm{t} 1: 3 .
\end{gathered}
$$

After computing these costs, the total annual cost of existing power plants (ETotalCost $t_{t}$ ) was obtained.

$$
\text { ETotalCost }_{t}=\text { EACPcost }_{t}+\text { EVARcost }_{t}+\text { EFIXEDcost }_{t}+\text { EFuelcost }_{t}+\text { ECarboncost }_{t} \quad \forall \mathrm{t} 1: 3 .
$$

This approach was also implemented for the new power plants $\mathrm{NIC}_{\tau, \mathrm{t}}$, as shown in the following equations:

$$
\begin{aligned}
& \mathrm{NACPCost}_{\mathrm{t}}=\sum_{\tau=1}^{10}\left(\mathrm{NIC}_{\tau, \mathrm{t}} \cdot \text { Capex }_{\tau}\right) \cdot\left(\frac{\mathrm{r}}{1-(1+\mathrm{r})^{-\mathrm{LT} \tau}}\right) \quad \forall \mathrm{t} 1: 3, \\
& \text { NFIXEDcost }_{\mathrm{t}}=\sum_{\tau=1}^{10}\left(\mathrm{NIC}_{\tau, \mathrm{t}} \cdot \text { Cfixed }_{\tau}\right) \quad \forall \mathrm{t} 1: 3, \\
& \text { NVARcost }_{\mathrm{t}}=\sum_{\tau=1}^{10}\left(\mathrm{NIC}_{\tau, \mathrm{t}} \cdot \mathrm{CF}_{\tau} \cdot \mathrm{OP} \cdot \mathrm{CVAR}_{\tau}\right) \quad \forall \mathrm{t} 1: 3, \\
& \text { NFuelcost }_{t}=\sum_{\tau=1}^{10}\left(\mathrm{NIC}_{\tau, \mathrm{t}} \cdot \mathrm{CF}_{\tau} \cdot \mathrm{OP} \cdot \mathrm{Cfuel}_{\tau}\right) \quad \forall \mathrm{t} 1: 3, \\
& \text { NCarboncost }_{\mathrm{t}}=\sum_{\tau=1}^{10}\left(\mathrm{NIC}_{\tau, \mathrm{t}} \cdot \mathrm{CF}_{\tau} \cdot \mathrm{OP} \cdot \mathrm{Ctax}_{\tau} \cdot \mathrm{CO}_{2} \mathrm{rate}_{\tau}\right) \quad \forall \mathrm{t} 1: 3 \text {, } \\
& \text { NTotalCost }_{t}=\text { NACPcost }_{t}+\text { NVARcost }_{t}+\text { NFIXEDcost }_{t}+\text { NFuelcost }_{t}+\text { NCarbon }_{t} \quad \forall t 1: 3 .
\end{aligned}
$$

Subsequently, the total costs of both existing and new power plants are discounted to produce the net present value of the costs within each period $t$. The discounted total cost $\left(\mathrm{TDC}_{t}\right)$ was set as one of the objective functions.

$$
\text { Min }: \mathrm{TDC}_{\mathrm{t}}=\left(\text { NTotalCost }_{\mathrm{t}}+\mathrm{ETotalCost}_{\mathrm{t}}\right) \cdot\left(\frac{\mathrm{r}}{1-(1+\mathrm{r})^{\Delta \mathrm{t}}}\right) \quad \forall \mathrm{t} 1: 3
$$

\subsubsection{Minimising Carbon Emissions}

As the reduction of carbon emissions in the electricity sector is one of the top priorities in the climate change mitigation agenda, the model incorporated the minimisation of carbon emissions of existing and new power plants as an objective function.

$$
\begin{aligned}
& \mathrm{ECO}_{2} \mathrm{emitted}_{\mathrm{t}}=\sum_{\tau=1}^{10}\left(\mathrm{EIC}_{\tau, \mathrm{t}} \cdot \mathrm{CF}_{\tau} \cdot \mathrm{OP} \cdot \mathrm{CO}_{2} \text { rate }_{\mathrm{t}}\right) \quad \forall \mathrm{t} 1: 3, \\
& \mathrm{NCO}_{2} \mathrm{emitted}_{\mathrm{t}}=\sum_{\tau=1}^{10}\left(\mathrm{NIC}_{\tau, \mathrm{t}} \cdot \mathrm{CF}_{\tau} \cdot \mathrm{OP} \cdot \mathrm{CO}_{2} \text { rate }_{\mathrm{t}}\right) \quad \forall \mathrm{t} 1: 3, \\
& \text { Min : } \mathrm{CO}_{2} \text { emitted }_{\mathrm{t}}=\mathrm{NCO}_{2} \text { emitted }_{\mathrm{t}}+\mathrm{ECO}_{2} \text { emitted }_{\mathrm{t}} \quad \forall \mathrm{t} 1: 3 \text {. }
\end{aligned}
$$

\subsubsection{Minimising Land Use}

Land used by a certain technology is an important factor, as excessive use of land has severe implications, such as habitat and food displacement. Furthermore, in several occasions, it might be extremely challenging and costly to restore the land to its original state following the decommissioning of the power plant. The magnitude of these implications is particularly critical for nations with high 
population densities. Thus, land use was introduced to the model as one of the objective functions, in order to maintain land use at minimum levels.

$$
\begin{array}{cc}
\text { ELandused }_{\mathrm{t}}=\sum_{\tau=1}^{10}\left(\mathrm{EIC}_{\tau, \mathrm{t}} \cdot \mathrm{CF}_{\tau} \cdot \mathrm{OP} \cdot \mathrm{LU}_{\tau}\right) & \forall \mathrm{t} 1: 3, \\
\text { NLandused }_{\mathrm{t}}=\sum_{\tau=1}^{10}\left(\mathrm{NIC}_{\tau, \mathrm{t}} \cdot \mathrm{CF}_{\tau} \cdot \mathrm{OP} \cdot \mathrm{LU}_{\tau}\right) & \forall \mathrm{t} 1: 3, \\
\text { Min }: \mathrm{TLU}_{\mathrm{t}}=\text { ELandused }_{\mathrm{t}}+\text { NLandused }_{t} & \forall \mathrm{t} 1: 3 .
\end{array}
$$

\subsubsection{Minimising Social Opposition}

Due to the major impact of the energy sector on the society, the degree of social acceptability could play a key role in power expansion planning. Opposition might be the result of public perceptions regarding the potential catastrophic events and environmental impacts (aesthetic, odour, noise) of the energy technology/system. Factors affecting social acceptance of renewable energy technologies can be classified into personal, psychological and contextual [54]. Lack of social acceptance can hinder the development of a power plant. Hence, proposing a socially acceptable energy mix would ensure community's consensus for successful energy development plans. To this end, social opposition was introduced into the model to investigate how this criterion affects the final electricity mix.

Quantifying social opposition is a challenging task, as it is an arguably subjective indicator. In the context of this study, in order to find an effective way to quantify social opposition, we performed a literature review which indicated that a common approach is to rate the energy system/technology by means of an ordinal (with linguistic terms) [12,40,41] or a Likert scale [10,55], expressing the level of social acceptability or social opposition. Through this approach relative values are assigned to individual technologies, which are commonly collected through surveys [41].

In this study, data from Reference [10], derived from experts in the energy sector, were used for the quantification of the social opposition indicator. The study rated each technology in terms of social resistance at a scale of 1-5, ranging from the least to the highest social resistance. Moreover, the data was further converted into a percentage form as follows:

$$
\begin{gathered}
\left(\frac{\text { Rtech }_{\tau}-1}{5-1}\right) \cdot 100=\mathrm{SO}_{\tau}(\%) \quad \forall \tau 1: 10, \\
\text { Min : SocialOpposition }{ }_{\mathrm{t}}=\sum_{\tau=1}^{10}\left(\frac{\left(\mathrm{NIC}_{\tau, \mathrm{t}}+\mathrm{EIC}_{\tau, \mathrm{t}}\right) \cdot \mathrm{CF}_{\tau} \cdot \mathrm{OP}^{\mathrm{SO} \mathrm{SO}_{\tau}}}{\left.\sum_{\tau=1}^{10}\left(\mathrm{NIC}_{\tau, \mathrm{t}}+\mathrm{EIC}_{\tau, \mathrm{t}}\right) \cdot \mathrm{CF}_{\tau} \cdot \mathrm{OP}\right)}\right) \quad \forall \mathrm{t} 1: 3 .
\end{gathered}
$$

However, it should be noted that this approach bears some limitations. Social opposition is subject to temporality, as it tends to evolve over time and especially in the long run. Concerns on climate change impact society's opinion about low carbon energy sources, therefore leading to different acceptability rates through time. Furthermore, social opposition is expected to be sensitive in terms of geographical location; as such, data collected from Europe on social opposition rates may vary considerably from Indonesia's data.

\subsection{Additional Indicators}

Additional social indicators, namely the mortality rates and the number of jobs created, were included in the model to further investigate the impact of optimising the objective functions. These indicators could also assist in narrowing down the most suitable solution of the Pareto front generated from the multi-objective genetic algorithm. The overall potential mortality rate of the power generation mix (due to the operation and construction of the power plants) in each period was estimated using the following equation: 


$$
\text { Mortality }_{\mathrm{t}}=\sum_{\tau=1}^{10}\left(\left(\mathrm{EIC}_{\tau, \mathrm{t}}+\mathrm{NIC}_{\tau, \mathrm{t}}\right) \cdot \mathrm{CF}_{\tau} \cdot \mathrm{OP} \cdot \mathrm{MR}_{\tau}\right) \quad \forall \mathrm{t} 1: 3
$$

The number of jobs created was obtained from the following equation:

$$
\operatorname{Jobs}_{\mathrm{t}}=\sum_{\tau=1}^{10}\left(\mathrm{NIC}_{\tau, \mathrm{t}} \cdot \mathrm{JC}_{\tau}\right) \quad \forall \mathrm{t} 1: 3
$$

The number of jobs created, $\mathrm{JC}_{\tau}$ is an input value and has been estimated as a flat number per installed MW, per each technology, $\tau$.

\subsection{Constraints}

The constraints considered in the model are summarised in this section. Resilience requirements in the model are addressed through a series of constraints: applying a reserve margin on top of peak demand, setting net electricity production (after accounting for the plant's own use of electricity, transmission and distribution losses) higher than the projected power consumption, applying maximum percentage of imports, and ensuring the diversity of the electricity generation mix (by setting maximum proportion limits of intermittent power generation technologies also as a proxy for the maximum intermittent energy rate in the network). Further constraints imposed to electricity mix include requirements on renewable energy penetration, energy potential, annual construction limits, carbon emissions targets, social opposition, and land use limits.

\subsubsection{Required Capacity and Demand}

It is crucial that the sum of existing and newly installed capacities, minus the decommissioning capacities, is equal or greater than the required installed capacity at a certain period $\left(\mathrm{RIC}_{\mathrm{t}}\right)$ to ensure that the electricity demand is always met, thus preventing electricity breakdowns. $\mathrm{RIC}_{\mathrm{t}}$ is determined by Equation (25). The reserve margin Rmargin is a contingency factor that ensures sufficient capacities are built to withstand possible sudden electricity surges.

$$
\begin{gathered}
\mathrm{RIC}_{\mathrm{t}} \leq \sum_{\tau=1}^{10}\left(\mathrm{EIC}_{\tau, \mathrm{t}}+\mathrm{NIC}_{\tau, \mathrm{t}}-\mathrm{DIC}_{\tau, \mathrm{t}}\right) \quad \forall \mathrm{t} 1: 3, \\
\mathrm{RIC}_{\mathrm{t}}=\mathrm{PD}_{\mathrm{t}} \cdot(1+\text { Rmargin }) \quad \forall \mathrm{t} 1: 3 .
\end{gathered}
$$

Consumption growth is attributed to several factors, which include population growth, increase in electrification, and alleviation of poverty. Therefore, the net total power generated at a certain time period must exceed or be equal to the projected consumption at the corresponding time period $\left(\mathrm{CD}_{\mathrm{t}}\right)$. Energy demand growth was estimated based on historical changes.

$$
\begin{gathered}
\mathrm{CD}_{\mathrm{t}} \leq \sum_{\tau=1}^{10}\left(\operatorname{Pgen}_{\tau, \mathrm{t}} \cdot\left(1-\mathrm{O}_{\tau}-\mathrm{L}_{\tau}\right)\right) \quad \forall \mathrm{t} 1: 3, \\
\operatorname{Pgen}_{\tau, \mathrm{t}}=\left(\mathrm{EIC}_{\tau, \mathrm{t}}+\mathrm{NIC}_{\tau, \mathrm{t}}\right) \cdot \mathrm{CF}_{\tau} \cdot \mathrm{OP} \quad \forall \mathrm{t} 1: 3, \forall \tau 1: 10 .
\end{gathered}
$$

\subsubsection{Renewable Energy Penetration}

In order to ensure RE targets are satisfied per each period, the RE penetration constraint was incorporated into the model. In this case study, RE targets were set at 15, 20, and 25\% for 2020, 2025, and 2030, respectively.

$$
\text { REtarget }_{\mathrm{t}} \leq \frac{\sum_{\tau=4}^{10}\left(\mathrm{EIC}_{\tau, \mathrm{t}}+\mathrm{NIC}_{\tau, \mathrm{t}}\right) \cdot \mathrm{CF}_{\tau} \cdot \mathrm{OP}}{\sum_{\tau=1}^{10}\left(\mathrm{EIC}_{\tau, \mathrm{t}}+\mathrm{NIC}_{\tau, \mathrm{t}}\right) \cdot \mathrm{CF}_{\tau} \cdot \mathrm{OP}} \quad \forall \mathrm{t} 1: 3
$$




\subsubsection{Energy Diversity}

Energy diversity is of paramount importance, as it contributes to the energy resilience of the region. Having a diverse energy mix decreases the risk of issues related to intermittency and continuity on the overall electricity production of the system. To ensure diversity, the following constraint was introduced into the model, imposing a maximum limit on the fractional contribution of each technology in the final power generation mix, Maxprop ${ }_{\tau, t}$.

$$
\text { Maxprop }_{\tau, \mathrm{t}} \geq \frac{\left(\mathrm{EIC}_{\tau, \mathrm{t}}+\mathrm{NIC}_{\tau, \mathrm{t}}\right) \cdot \mathrm{CF}_{\tau} \cdot \mathrm{OP}}{\sum_{\tau=1}^{10}\left(\mathrm{EIC}_{\tau, \mathrm{t}}+\mathrm{NIC}_{\tau, \mathrm{t}}\right) \cdot \mathrm{CF}_{\tau} \cdot \mathrm{OP}} \quad \forall \mathrm{t} 1: 3, \forall \tau 1: 10 .
$$

\subsubsection{Import Dependency}

The extent of import dependency could have an impact on the energy security of a nation. High dependency on external sources creates great risk as rising conflicts, or instability of these exporting countries would lead to potential consequences. These include electricity shortage and increased costs of technology deployment. As a result, the following constraint was added to ensure that the level of imports (mostly of fossil fuels) is acceptable [56].

$$
\mathrm{IDR}_{\mathrm{t}} \geq \frac{\sum_{\tau=1}^{3}\left(\mathrm{EIC}_{\tau, \mathrm{t}}+\mathrm{NIC}_{\tau, \mathrm{t}}\right) \cdot \mathrm{CF}_{\tau} \cdot \mathrm{OP} \cdot\left(\frac{\mathrm{IMPnet}}{\text { Supply }+\mathrm{IMPnet}}\right)}{\mathrm{CD}_{\mathrm{t}}} \quad \forall \mathrm{t} 1: 3 .
$$

\subsubsection{Energy Potential}

To ensure that the installed capacity of each technology, at a given period, does not exceed the potential of the geographical region, the following constraint was formulated:

$$
\text { EPotcap }_{\tau, \mathrm{t}} \geq\left(\mathrm{EIC}_{\tau, \mathrm{t}}+\mathrm{NIC}_{\tau, \mathrm{t}}\right) \quad \forall \mathrm{t} 1: 3, \forall \tau 1: 10
$$

\subsubsection{Construction Limit}

Construction limits depend on several factors, such as labour and land availability and the size of manufacturing technologies. Consequently, the following constraint was added to account for the construction limit.

$$
\text { CONlimit }_{\tau, \mathrm{t}} \cdot \Delta \mathrm{t} \geq \mathrm{NIC}_{\tau, \mathrm{t}} \quad \forall \mathrm{t} 1: 3, \forall \tau 1: 10 .
$$

\subsubsection{Carbon Emissions Target}

The carbon emissions reduction target, when not used as the objective function, it was considered as a constraint, setting the total amount of $\mathrm{CO}_{2, \text { eq }}$ emissions at a maximum limit:

$$
\mathrm{CO}_{2} \text { target }_{\mathrm{t}} \geq \sum_{\tau=1}^{10}\left(\left(\mathrm{EIC}_{\tau, \mathrm{t}}+\mathrm{NIC}_{\tau, \mathrm{t}}\right) \cdot \mathrm{CF}_{\tau} \cdot \mathrm{OP} \cdot \mathrm{CO}_{2} \text { rate }_{\tau}\right) \quad \forall \mathrm{t} 1: 3 .
$$

\subsubsection{Social Opposition Constraint}

Social opposition was also set as a constraint, when not used as an objective function, setting a maximum total amount of social opposition target for the whole power generation system.

$$
\text { SOtarget }_{\mathrm{t}} \geq \sum_{\tau=1}^{10}\left(\frac{\left(\mathrm{NIC}_{\tau, \mathrm{t}}+\mathrm{EIC}_{\tau, \mathrm{t}}\right) \cdot \mathrm{CF}_{\tau} \cdot \mathrm{OP} \cdot \mathrm{SO}_{\tau}}{\sum_{\tau=1}^{10}\left(\left(\mathrm{NIC}_{\tau, \mathrm{t}}+\mathrm{EIC}_{\tau, \mathrm{t}}\right) \cdot \mathrm{CF} \tau \cdot \mathrm{OP}\right)}\right) \quad \forall \mathrm{t} 1: 3
$$

\subsubsection{Land Use Constraint}

Same as the carbon emissions and social opposition, total land use was added as a constraint, as follows: 


$$
\text { LUtarget }_{\mathrm{t}} \geq \sum_{\tau=1}^{10}\left(\left(\mathrm{EIC}_{\tau, \mathrm{t}}+\mathrm{NIC}_{\tau, \mathrm{t}}\right) \cdot \mathrm{CF}_{\tau} \cdot \mathrm{OP} \cdot \mathrm{LU}_{\tau}\right) \quad \forall \mathrm{t} 1: 3
$$

Attention should be paid to the mathematical formulation of above relationships, which depend on the units of the input parameters and their modelling approach (e.g., as a function of energy production, installed capacity or as a percentage). For example, the input parameter jobs creation $\left(\mathrm{JC}_{\tau}\right)$ is measured in $\frac{\text { number of jobs }}{\mathrm{MW}}$, the land use $\left(\mathrm{LU}_{\tau}\right)$ in $\frac{\mathrm{m}^{2}}{\mathrm{MWh}}$, and the social opposition $\left(\mathrm{SO}_{\tau}\right)$ as a percentage.

\section{Case Study}

\subsection{Indonesian Context}

Indonesia is an island country consisting of over 17,000 islands, which is situated within Southeast Asia and Oceania [57]. It is the forth country with the largest population in the world, amounting to approximately 270 million people [58]. Indonesia was selected as the case study of this work, due to the country's significant fossil fuel reserves and significant unexploited RE potential. This is beneficial as the integrity and robustness of the model can be carefully examined, since a diverse set of energy technologies can be assessed and subsequently introduced into the generation mix.

Indonesia's economy is considered the largest in the region, with a steady annual growth rate of $5 \%$ since 1999, which dates back to the Asian financial crisis. Additionally, the gross domestic product (GDP) was equivalent to $\$ 932$ billion in year 2016. The main driver of its largely growing economy sector was the exportation of oil. However, in 2004 the country became an oil importer and began to diversify its economy through activities, such as domestic manufacturing and investment. Other notable activities in Indonesia include agriculture, forestry, fishing, mining, construction, and services associated with motor vehicles [57].

The growth and diversification of Indonesia's economy was of paramount importance in the reduction of poverty on a national scale. Poverty reduced from approximately 23 to $12 \%$ in 2016 . However, this is still a considerable value as it represented around 28 million people [59]. In addition to alleviation of poverty, energy security remains a great challenge in Indonesia. This is because Indonesia's distinctive geographic characteristics present challenges in guaranteeing that nation-wide electricity access is available. An ideal solution to this challenge is to ensure a diverse energy portfolio, which calls for the reduction of fossil fuel dependence and exploitation of alternative RE sources.

Furthermore, the significant growth of both economy and population consequently implicates increased energy consumption, as witnessed by the increase in energy demand by $4.9 \%$ in 2018 , while the economic growth was recorded at 5.2\% [60]. In addition, as shown in Figure 5, it is estimated that electricity consumption will increase approximately 5\% annually from 2013 to 2027 [61]. This could be an important challenge if the expansion of the energy system is not properly planned. To add to that, in 2018, $45 \%$ of the increase in energy consumption was satisfied by oil [60]. Thus, generating a cost efficient, decentralized, and diverse energy portfolio that supports environmental and social regulations would greatly reduce the associated risks. 


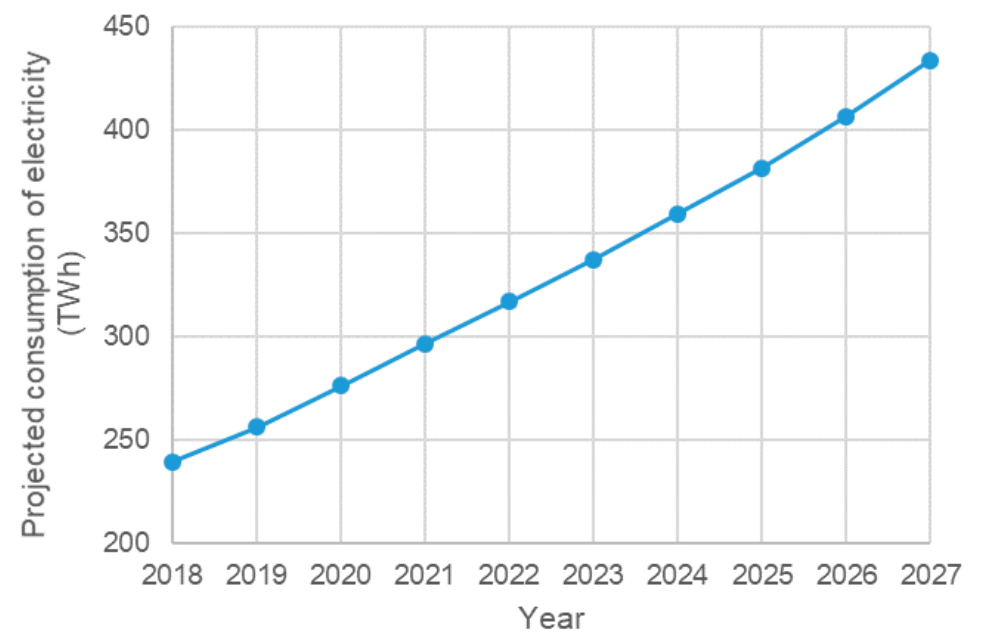

Figure 5. Forecasted electricity consumption in Indonesia (based on data collected from Reference [62]).

\subsection{Energy Situation and Prospects in Indonesia}

\subsubsection{Coal, Oil and Gas}

Indonesia has an abundant supply of fossil fuels, and remains a net energy exporter. In 2004, oil consumption in Indonesia has exceeded oil production, which resulted in increasing its imports of oil and oil products. In addition, oil production in Indonesia began to decrease due to the depletion of current oil fields, along with the fact that new potential oil reserves in the region require expensive and complex methods of extraction [60]. This adds an additional risk to Indonesia's energy security, as operating under a 'business as usual' scenario would eventually lead to high import dependence within the next few decades [57]. Therefore, reducing fossil fuel, specifically oil, consumption in the power sector could potentially offset the increased consumption within the transport industry.

Coal production in Indonesia witnessed a sharp increase in the recent few years [63]. The low cost and high calorific value of Indonesia's coal has led to market dominance in Asia, where the largest markets were in China and India. However, Indonesia recently promoted the domestic consumption of coal to inhibit the increase of oil import dependency. Unfortunately, domestic reliance of coal will prevent Indonesia from achieving its low carbon footprint targets.

Indonesia has a total of approximately 150 trillion cubic feet of gas reserves, and its supply is projected to grow at an average rate of $2.3 \%$ annually until 2025. Therefore, with the removal of administrative issues and enhanced development, gas has the potential to substitute domestic coal consumption in the power sector. This will result in a relatively lower carbon footprint, at least until $R E$ technologies are robust and financially competitive to satisfy a dominant portion of the energy $\operatorname{mix}[63]$.

\subsubsection{Geothermal}

Due to Indonesia's unique geographic properties, the nation has one of the greatest geothermal potential globally, estimated at approximately 29 Gigawatts (GW). The presence of numerous volcanoes within Indonesia, known as "the ring of fire", leads to a large pool of high-temperature gradients within its sub-surface providing a high geothermal potential [64]. In addition to its abundancy, unlike many other alternative sources, geothermal energy is a baseload type of energy and it is weather-independent, eliminating issues, such as intermittency and storage requirements. As a result, it is aimed to produce a total geothermal capacity of $9000 \mathrm{MW}$ by the year 2050 [65]. However, this target was deemed unrealistic since 11 geothermal plants were operational in 2016 with a total capacity of only 1530 MW [47]. Nevertheless, with the appropriate policies and regulations being implemented, geothermal has the potential to substitute a significant portion of coal and oil in the power sector. 


\subsubsection{Biomass}

In terms of biomass-derived power, the total potential is estimated at approximately $33 \mathrm{GW}$. This is mainly derived from palm oil, followed by rice husk, sugar cane, cow manure, solid wood, corn, natural rubber, and municipal solid waste. Despite the promising high potential, only 7 GW is predicted to be utilized by 2030 [66]. The utilization of biomass as an energy source could expand to a wider array of benefits, which include heat, transport, and even waste elimination [67]. Therefore, policies should be placed to ensure sufficient consideration is given to biomass and its promising gains to Indonesia.

\subsubsection{Hydro}

Hydropower is a baseload and dispatchable form of renewable power generation, in which it is independent of weather variations, thus lack intermittency issues. Indonesia's potential of hydro energy is estimated at $75 \mathrm{GW}$. These features include the availability of ample amounts of rivers that can be exploited for hydro power plant installations. However, only $7 \%$ of this potential was utilised up to 2015 [68].

\subsubsection{Solar}

Indonesia lies across the Equator with daylight readily available throughout the year providing significant solar energy potential in the region amounting to approximately $207 \mathrm{GW}$ [69]; however, only 11 MW capacity has been installed up to 2015. The Indonesian government aims to expand the utilization of solar energy, and, to this end, it has introduced a feed-in tariff policy [70]. Solar panels have mainly been installed in Java, Bali, and Papua due to the high irradiance, low population density, and large amount of land available [71].

\subsubsection{Wind}

Wind has historically been the least exploited RE resource in Indonesia, due to the uncertainty induced by the intermittency of wind energy in the region. Current wind power developments in the nation are typically situated in remote locations, specifically in Java and Madura islands [72]. Wind power projects are projected to increase in the future and reach up to $2.6 \mathrm{GW}$ installed capacity by 2030 [73].

\subsection{Technology Data}

This section presents the input data of the model. It should be noted that only currently available energy sources in Indonesia, as well as widely deployed renewable energy technologies (onshore/offshore wind, CSP, solar PV, geothermal, biomass), were included as inputs in the analysis. Other emerging technologies, such as the Carbon Capture and Storage (CCS) technology, was not included, as cost of CCS is still quite high and without the appropriate level of policy support, the technology will not kick off. Table 3 illustrates the environmental and social input data, while Tables 4 and 5 the technical and cost data for each technology, respectively. Finally, Table 6 summarises the existing power plant capacities in the starting year of the simulation (i.e., the year 2016), and Table 7 summarises the proportion limits set to maintain diversity. 
Table 3. Environmental and social input data for each technology ${ }^{1}$.

\begin{tabular}{|c|c|c|c|c|c|}
\hline Technology & $\begin{array}{c}\mathrm{CO}_{2, \mathrm{eq}} \text { Emissions } \\
\left(\mathrm{tCO} \mathrm{C}_{2, \mathrm{eq}} / \mathrm{MWh}\right)\end{array}$ & $\begin{array}{l}\text { Land Use } \\
\left(\mathrm{m}^{2} / \mathrm{MWh}\right)\end{array}$ & $\begin{array}{c}\text { Social Opposition } \\
(\%)\end{array}$ & $\begin{array}{c}\text { Jobs Created } \\
\text { (Jobs/MW) }\end{array}$ & $\begin{array}{c}\text { Mortality Rates } \\
\text { (Deaths/PWh) }\end{array}$ \\
\hline Coal (PCF) & 1.08 & 0.2 & 60 & 0.80 & 100,000 \\
\hline Gas (NGCC) & 0.50 & 0.2 & 48 & 0.80 & 4000 \\
\hline Diesel & 0.80 & 0.4 & 54 & 0.80 & 36,000 \\
\hline Hydro & 0 & 10.0 & 55 & 1.28 & 1400 \\
\hline Geothermal & 0 & 2.5 & 25 & 2.17 & 1000 \\
\hline Biomass & 0 & 500.0 & 30 & 1.80 & 24,000 \\
\hline Wind Onshore & 0 & 1.0 & 55 & 0.52 & 150 \\
\hline Wind Offshore & 0 & 1.0 & 33 & 0.52 & 150 \\
\hline Solar PV & 0 & 10.0 & 20 & 1.52 & 440 \\
\hline Solar CSP & 0 & 15.0 & 20 & 0.81 & 400 \\
\hline
\end{tabular}

${ }^{1}$ References for $\mathrm{CO}_{2, \text { eq }}$ emissions [50], land use [74], social opposition [10], jobs created [75], and mortality rates [76].

Table 4. Environmental and social input data for each technology ${ }^{1}$.

\begin{tabular}{ccccc}
\hline Technology & Capacity Factor (\%) & Lifetime (Years) & $\begin{array}{c}\text { Renewable } \\
\text { Potential (MW) }\end{array}$ & $\begin{array}{c}\text { Construction } \\
\text { Limit (MW/Year) }\end{array}$ \\
\hline Coal (PCF) & 70 & 30 & - & - \\
Gas (NGCC) & 70 & 30 & - & - \\
Diesel & 70 & 30 & - & - \\
Hydro & 63 & 40 & 75,670 & 1600 \\
Geothermal & 85 & 30 & 28,910 & 1000 \\
Biomass & 56 & 20 & 32,654 & 1300 \\
Wind Onshore & 30 & 30 & 60,600 & 1000 \\
Wind Offshore & 41 & 25 & 60,600 & 50 \\
Solar PV & 21 & 25 & 207,800 & 8500 \\
Solar CSP & 52 & 20 & 207,800 & 30 \\
\hline
\end{tabular}

${ }^{1}$ References for capacity factor [77], renewable potential [69], lifetime, and construction limit [8].

Table 5. Cost input data for each technology ${ }^{1}$.

\begin{tabular}{|c|c|c|c|c|}
\hline Technology & Capex Cost (\$/kW) & Fuel Cost (\$/MWh) & Variable (\$/MWh) & Fixed Cost (\$/kW-Year) \\
\hline Coal (PCF) & 3600 & 12 & 5 & 33.1 \\
\hline Gas (NGCC) & 882 & 37 & 6 & 17.1 \\
\hline Diesel & 700 & 58 & 6 & 11.0 \\
\hline Hydro & 4600 & 0 & - & 75.0 \\
\hline Geothermal & 5200 & 0 & - & 152.0 \\
\hline Biomass & 4000 & 25 & 5 & 58.0 \\
\hline Wind Onshore & 1615 & 0 & - & 51.0 \\
\hline Wind Offshore & 6100 & 0 & - & 132.0 \\
\hline Solar PV & 2600 & 0 & - & 18.0 \\
\hline Solar CSP & 7872 & 0 & 4.1 & 67.0 \\
\hline
\end{tabular}

${ }^{1}$ References for Capex, variable and fixed costs $[8,77]$ and fuel costs [78-80].

Table 6. Definition of variables.

\begin{tabular}{cc}
\hline Technology & Capacity in 2016 (MW) \\
\hline Coal & 25,697 \\
Natural Gas & 17,964 \\
Diesel & 635,294 \\
Hydro & 5342 \\
Geothermal & 1435 \\
Biomass & 86 \\
Wind onshore & 1 \\
Solar PV & 11 \\
\hline Total & 56,932 \\
\hline
\end{tabular}


Table 7. Proportion limits set to maintain diversity.

\begin{tabular}{cccc}
\hline Technology & $\mathbf{2 0 2 0}$ & $\mathbf{2 0 2 5}$ & $\mathbf{2 0 3 0}$ \\
\hline Coal (PCF) & 50 & 50 & 50 \\
Gas (NGCC) & 40 & 40 & 40 \\
Diesel * & 10 & 8 & 5 \\
Hydro & 30 & 30 & 30 \\
Geothermal & 30 & 30 & 30 \\
Biomass & 30 & 30 & 30 \\
Wind Onshore & 30 & 30 & 30 \\
Wind Offshore & 30 & 30 & 30 \\
Solar PV & 30 & 30 & 30 \\
Solar CSP & 30 & 30 & 30
\end{tabular}

* Diesel technologies had relatively low maximum proportion limits to prevent the risk of requiring oil imports for power production.

\section{Results and Discussion}

\subsection{Single-Objective Optimisation Results}

Before the application of the MO, single-objective linear optimisations were performed to investigate how each objective individually influences the power generation mix of the region. Five optimisation case studies were performed, including: (i) Minimisation of discounted cost, (ii) Minimisation of discounted cost with carbon emission targets as constraints, (iii) Minimisation of carbon emissions, (iv) Minimisation of land use, and (v) Minimisation of social opposition. The single-optimisations were solved as constrained linear programming problems.

The optimal power generation technology mixes are shown in Figures 6-8 for the three periods analysed. Similarities are present amongst each case study during 2020. This is due to the fact that existing plants already meet a significant portion of the demand and are yet far away from being decommissioned. While the variations during this period are slightly vague, a clear divergence is witnessed in 2030 (Figure 6).

Starting with the minimisation of the discounted costs scenario, the power generation mix was mainly dominated by fossil fuel technologies, with the exception of a small portion of onshore wind and solar because of their lower costs. Due to the higher cost of other renewables, this scenario did not favour the transition to higher RE shares. On the other hand, the cost-optimised scenario with carbon emission targets resulted in the substitution of more than half the share of coal with renewable technologies, such as geothermal and hydropower. In the minimising carbon emissions scenario, renewable technologies, namely biomass, hydro, geothermal, and solar PV, dominate the power generation mix. In terms of the minimum land use scenario, $95 \%$ of the power is generated by fossil fuel technologies, suggesting that setting the minimum land use as the key driver would result in a high carbon footprint; hence, there is an inverse relationship between land use and carbon emissions.

With regard to hydro power, social opposition is relatively high due to its potential consequences, such as land displacements and occurrence of major accidents [81]. As far as onshore wind is concerned, the community tends to have a negative perception due to the associated noise and visual pollution of the technology. On the other hand, while offshore wind has a relatively higher social acceptability, the technical construction limit prevents it from acquiring very high shares in the power generation mix. Gas is also relatively socially acceptable compared to technologies, such as coal and hydro. 


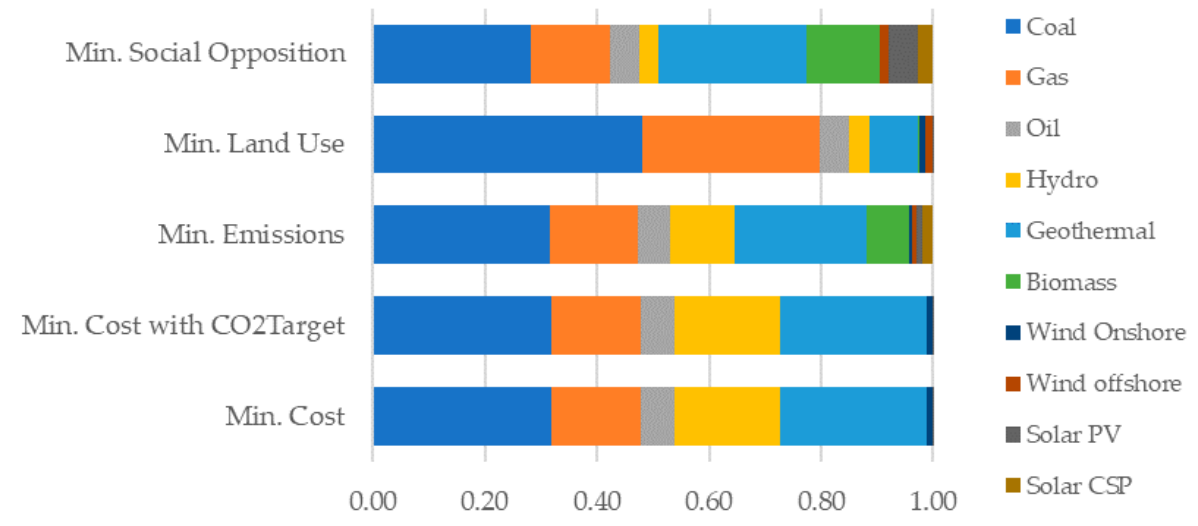

Figure 6. Power generation mix under the single objective scenarios in 2020.

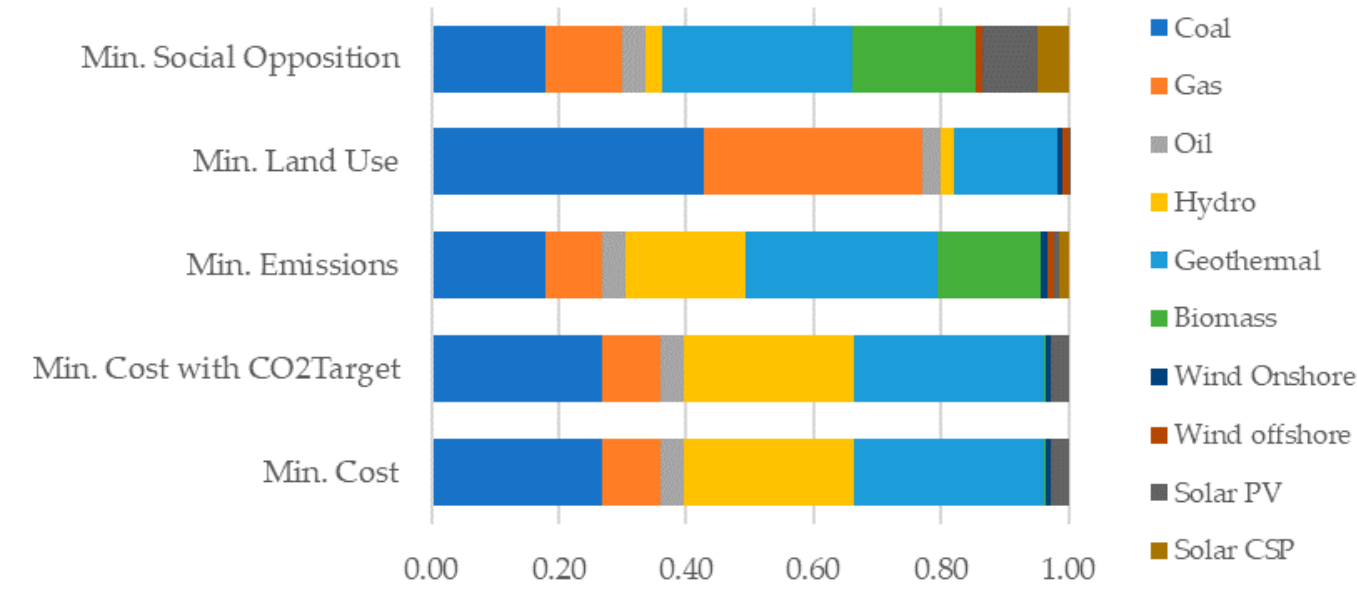

Figure 7. Power generation mix under the single objective scenarios in 2025.

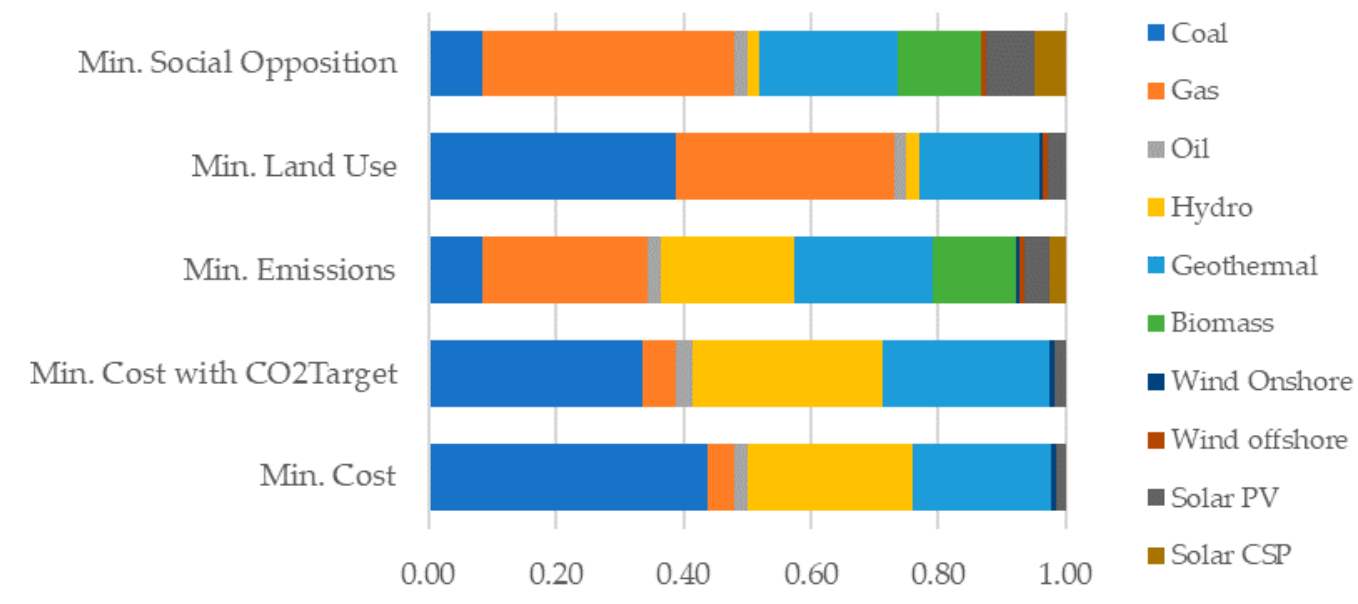

Figure 8. Power generation mix under the single objective scenarios in 2030.

Social opposition and land use appeared to lead to quite dissimilar optimal power generation technology combinations. In conclusion, while some similarities were observed across all case scenarios, the integration of selected objective functions is bound to generate a balanced power generation mix. Minimisation of the land use promoted fossil fuel technologies, which is not desired for countries importing fossil fuel resources, since it could threaten their energy security. Furthermore, minimum costs favoured relatively cheap renewable technologies, along with fossil fuels. However, this could change dramatically with technological maturity of renewable technologies and the volatility of fuel 
prices. In addition, while minimum social opposition favoured solar, gas and biomass technologies, minimising carbon emissions promoted an overall transition away from fossil fuel technologies, hence providing a roughly equal share between RE technologies. In summary, it is important to acknowledge the fact that, regardless the objective function, coal and natural gas technologies will always remain in the mix. These technologies are essential to cope with the increase in demand, as well as compensate for the renewable technologies' construction limits and intermittency issues. The impact of the different objective functions on a number of selected indicators is demonstrated in Figure $9 \mathrm{a}-\mathrm{h}$.

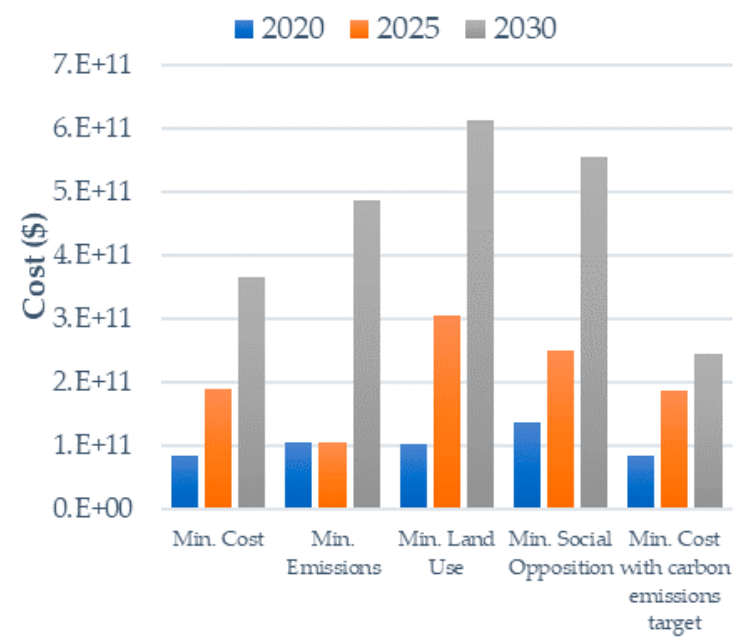

(a)

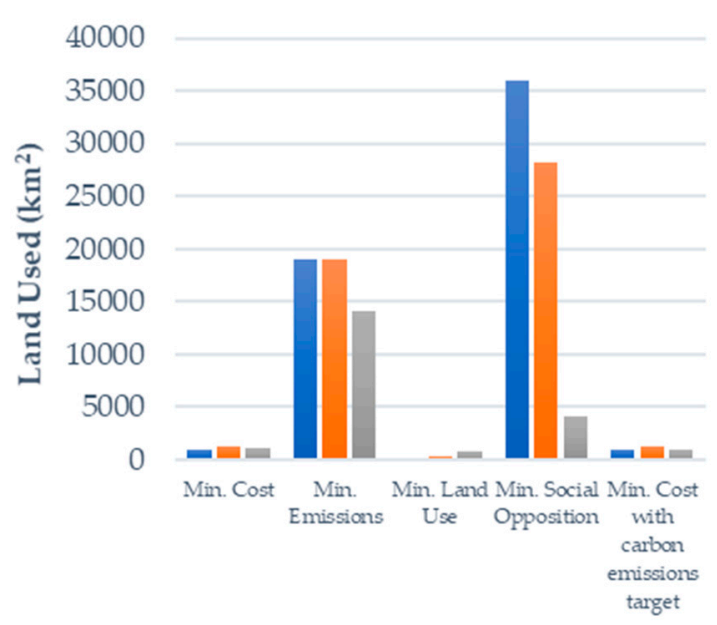

(c)

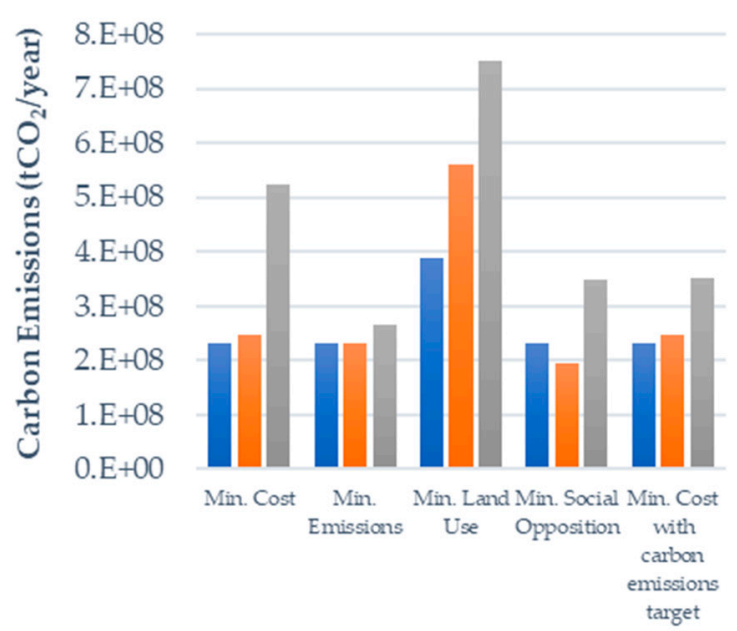

(b)

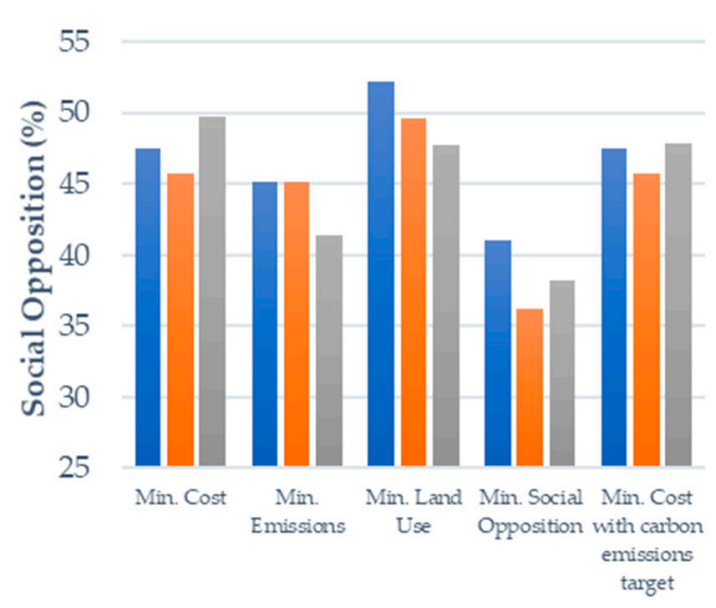

(d)

Figure 9. Cont. 


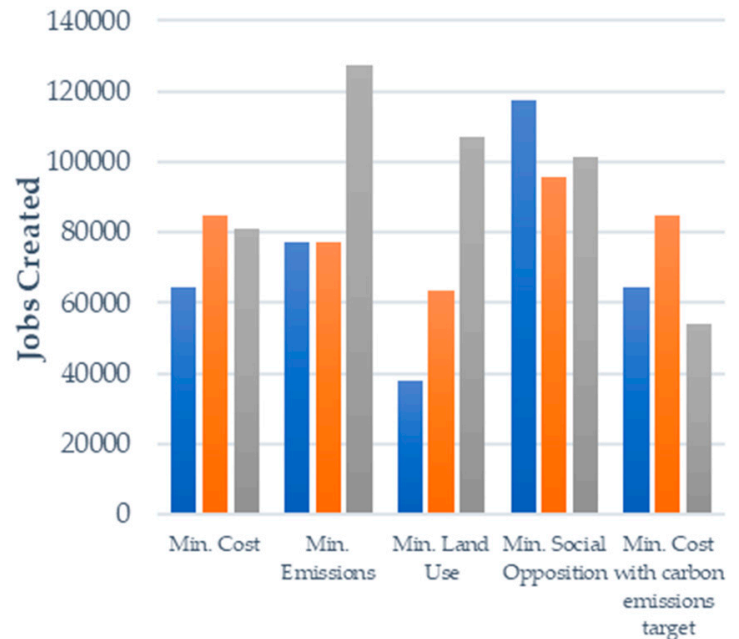

(e)

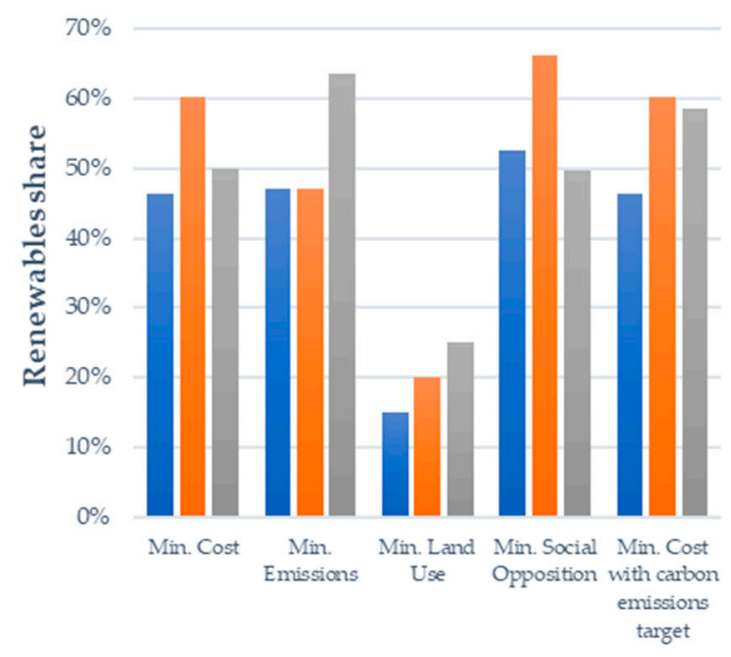

(g)

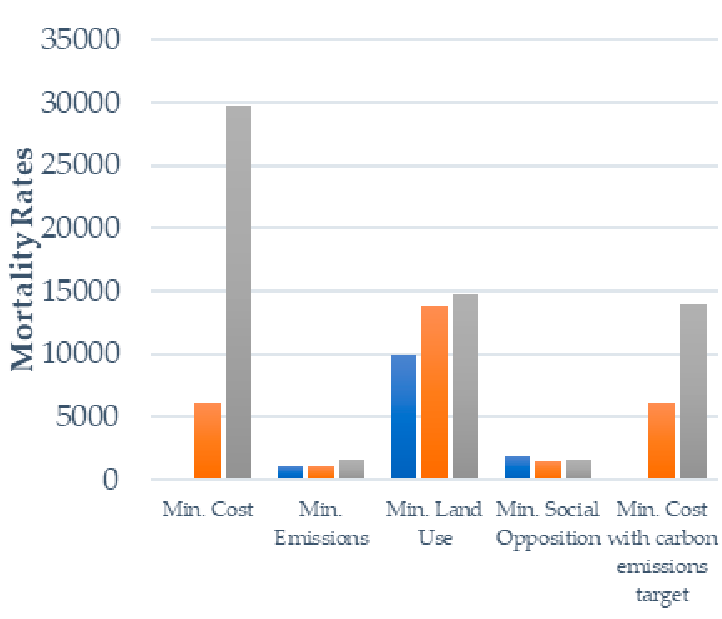

(f)

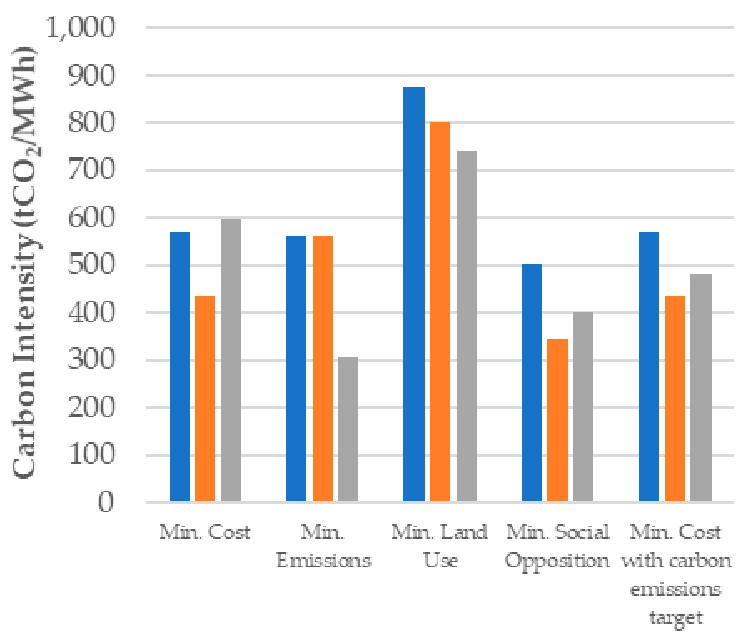

(h)

Figure 9. Impact of individual scenarios on selected indicators across each period: (a) discounted costs, (b) $\mathrm{CO}_{2, \text { eq }}$ emissions, (c) land use, (d) social opposition, (e) jobs created, (f) mortality rates, (g) renewable share, and (h) carbon intensity.

As far as total cost is concerned, the minimum value was expectedly realised under the cost-minimisation scenarios (with and without the carbon emissions target), followed by the social opposition minimisation scenario. Social opposition promoted the use of relatively inexpensive renewable technologies, such as biomass and solar PV. Furthermore, as hydropower and geothermal technologies are generally more capital-intensive, the minimisation of carbon emissions scenario yielded a greater cost in comparison to the social opposition one. In 2030, the land use scenario induced the highest cost due to the elimination of RE technologies, such as solar PV and onshore wind, which become progressively less expensive due to learning curve effects.

Apart from the carbon emissions scenario, low carbon emissions were also observed in the social opposition scenario, as a large proportion of RE technologies was introduced in the power generation mix. On the other hand, the land use scenario induced the highest carbon emissions due to the domination of fossil fuels. The discounted cost scenario generally yielded a balanced power generation mix accommodating a considerable amount of generated power from solar PV and onshore wind technologies. Apart from the land use scenario, which favoured the use of fossil fuel technologies, the carbon intensity of all scenarios decreased in the course of time, with social and carbon optimised scenarios decreasing to the greatest extent. 
The RE share across all scenarios can be observed in Figure $9 g$, where the highest amount was observed in the carbon emissions scenario, followed by the social opposition scenario. A smoother transition to RE technologies was observed under the social opposition scenario, as natural gas, which is a relatively socially acceptable technology, represented a major portion in the mix. In the carbon emissions scenario, this was compensated by renewable technologies, such as hydro and geothermal power. Due to the absence of any transition towards renewables, the land-optimised case study had the lowest RE share.

The additional indicators, namely the mortality rates and the jobs created, were incorporated into the model to develop a wider horizon of the magnitude of the impacts these criteria could potentially impose. The highest mortality rates were observed for the land use and discounted cost scenarios. In social and carbon emissions scenarios, low or negligible mortality rates were present because of the RE technology dominance. This further emphasised the strong correlation between social opposition and carbon emissions in certain occasions. The highest number of jobs was created under the carbon emissions (attributed to the installation of hydropower and onshore wind technologies) and social opposition scenarios. The social opposition of cost-optimal case studies was higher because of the fact that onshore wind and coal technologies, which normally have high opposition, were present in the mix. On the other hand, land use and carbon emissions were observed to be negatively correlated.

\subsection{Multi-Objective Optimisation Results}

To investigate the trade-offs among the objectives, Pareto front candidates for each pair of objective functions were derived from the model for the first optimisation period (2020). The objective function values for Pareto-front solutions are presented in Figure 10a- $\mathrm{f}$ for three non-dominated solutions, two extremes corresponding to the minimum values of the two objective functions and a compromise value of the objective functions. The extreme solutions, i.e., the new built capacities per technology, corresponding to the minimum values of each objective function, along with the compromise solution (in between of the two extremes) were retrieved from the optimisation exercise, and their values can be found in Table 8.

Decision-makers can choose the solution that is the most appropriate through studying the trade-offs between each objective function. As it can be observed from Table 8, values of the extreme solutions of the cost minimisation objective function remain the same across all Pareto fronts, and include the lowest amount of renewable energy capacity additions compared to the rest of the cases. Table 8 reveals that there is a strong correlation between the minimisation of annual $\mathrm{CO}_{2, \text { eq }}$ emissions (OF2) and the social opposition (OF4) solutions, as similar output capacities were observed across the different power plant types. Limited trade-offs can also be observed between the minimisation of costs (OF1) and minimisation of land use (OF3) solutions.

From above analysis, it was deduced that due to the strong correlation of OF2 with OF4, as well as the OF1 with OF3, the multi-objective optimisation problem can be reduced to integrate two objective functions, namely the minimisation of annual cost and the $\mathrm{CO}_{2, \text { eq }}$ emissions, removing the social opposition and land use objectives. The two objective functions were integrated in the bi-objective optimisation model for the first two periods (from 2016 to 2020 and from 2020 to 2025). A series of 70 non-dominated solutions were generated in the first period, followed by 4900 solutions in the second period. In the final period, the power generation mixes of the previous period were optimised in terms of total cost by means of a linear optimisation problem, including a carbon tax with an assumed value of $30 \$ / \mathrm{tCO}_{2, \text { eq }}$ and the cumulative impact of the objective functions on the resulting power generation mix was investigated. It should be noted that removing the duplicated, non-dominated solutions existing in each final generation, before advancing to the subsequent period, is likely to reduce the number of final solutions, increasing the efficiency of the model, and is suggested to be investigated in future application of this framework. 


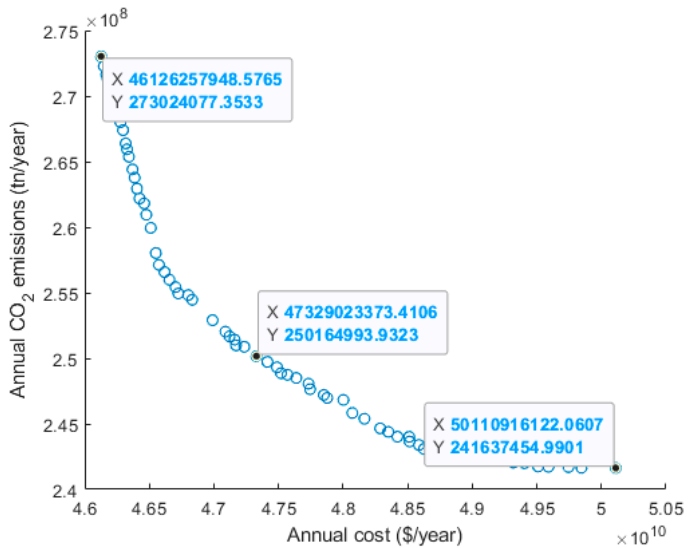

(a)

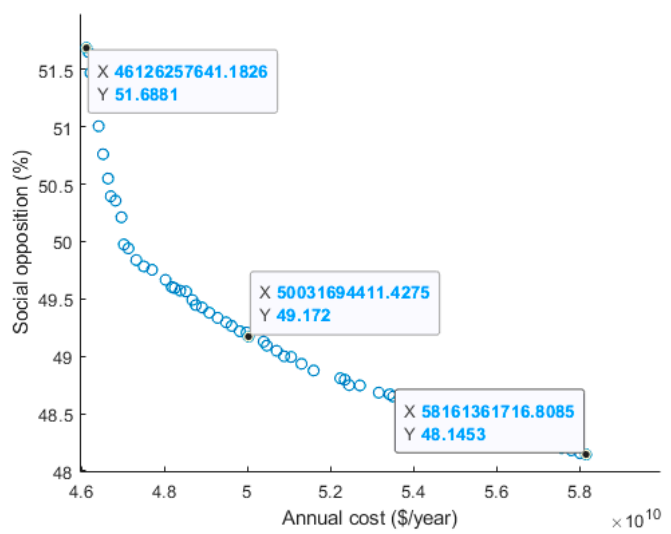

(c)

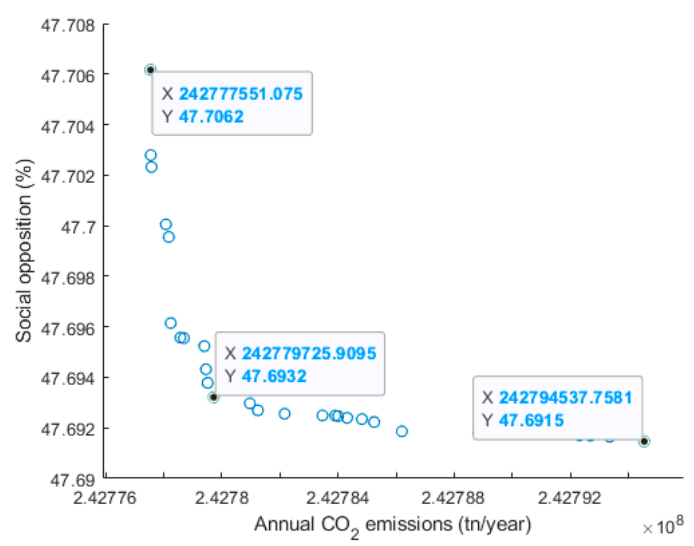

(e)

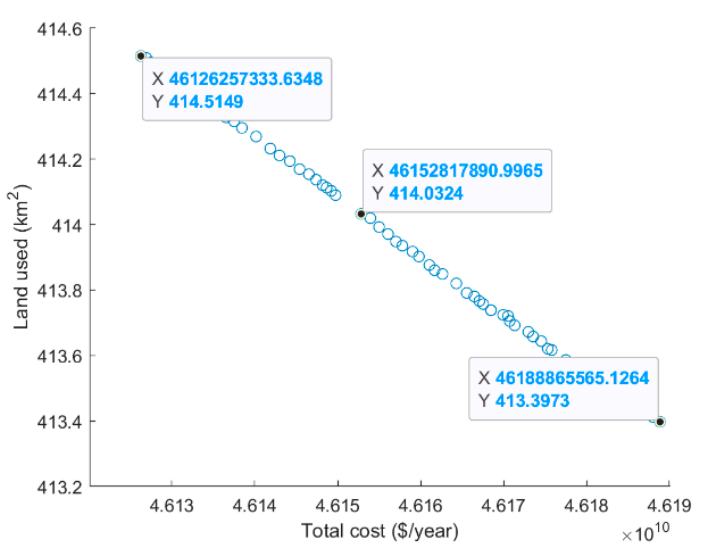

(b)

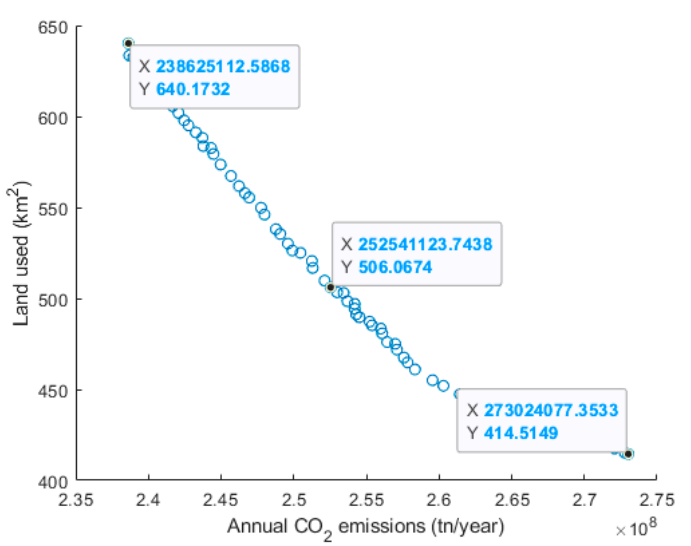

(d)

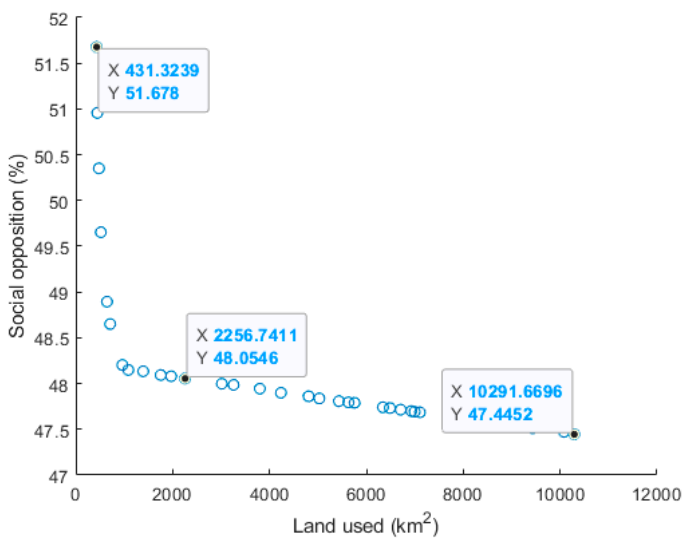

(f)

Figure 10. Pareto front candidates indicating trade-offs between: (a) Annual costs and annual $\mathrm{CO}_{2, \mathrm{eq}}$ emissions; (b) Annual costs and land use; (c) Annual costs and social opposition; (d) Annual $\mathrm{CO}_{2, \mathrm{eq}}$ emissions and land use, (e) Annual $\mathrm{CO}_{2, \text { eq }}$ emissions and social opposition, and (f) land use and social opposition. 
Table 8. Extreme and compromise solutions of candidate Pareto fronts per pair of objective functions (for 2020 period).

\begin{tabular}{|c|c|c|c|c|c|c|c|c|c|c|c|}
\hline \multirow{2}{*}{$\begin{array}{l}\text { Pair of Objective } \\
\text { Functions }\end{array}$} & \multirow{2}{*}{$\begin{array}{l}\text { Points of the } \\
\text { Pareto Front }\end{array}$} & \multicolumn{10}{|c|}{ New Additions of Power Generation Capacity (MW) in 2020} \\
\hline & & 1 & 2 & 3 & 4 & 5 & 6 & 7 & 8 & 9 & 10 \\
\hline \multirow{3}{*}{$\mathrm{OF} 1 / 2$ * } & MinOF1 & 4736 & 1414 & 0 & 0 & 0 & 0 & 4000 & 0 & 21,493 & 0 \\
\hline & MinOF2 & 167 & 2053 & 171 & 344 & 876 & 3694 & 3899 & 27 & 21,659 & 46 \\
\hline & Compromise & 1103 & 2323 & 259 & 777 & 1202 & 639 & 3800 & 36 & 21,722 & 50 \\
\hline \multirow{3}{*}{ OF1/3 } & MinOF1 & 4736 & 1414 & 0 & 0 & 0 & 0 & 4000 & 0 & 21,493 & 0 \\
\hline & MinOF3 & 4736 & 1414 & 59 & 0 & 1 & 0 & 4000 & 0 & 21,420 & 0 \\
\hline & Compromise & 4736 & 1414 & 25 & 0 & 0 & 0 & 4000 & 0 & 21,462 & 0 \\
\hline \multirow{3}{*}{$\mathrm{OF} 1 / 4$} & MinOF1 & 4736 & 1414 & 0 & 0 & 0 & 0 & 4000 & 0 & 21,493 & 0 \\
\hline & MinOF4 & 2050 & 1543 & 94 & 142 & 3889 & 3626 & 2781 & 23 & 25,792 & 39 \\
\hline & Compromise & 2058 & 1481 & 27 & 82 & 3547 & 73 & 2822 & 16 & 24,441 & 24 \\
\hline \multirow{3}{*}{$\mathrm{OF} 2 / 3$} & MinOF2 & 115 & 1448 & 82 & 3254 & 1671 & 3 & 3896 & 45 & 21,520 & 26 \\
\hline & MinOF3 & 4736 & 1414 & 0 & 0 & 0 & 0 & 4000 & 0 & 21,493 & 0 \\
\hline & Compromise & 1970 & 1436 & 68 & 958 & 1710 & 2 & 3939 & 48 & 21,528 & 18 \\
\hline \multirow{3}{*}{$\mathrm{OF} 2 / 4$} & MinOF2 & 597 & 1359 & 227 & 941 & 3615 & 4611 & 3434 & 76 & 27,518 & 46 \\
\hline & MinOF4 & 598 & 1360 & 229 & 906 & 3623 & 4627 & 3431 & 77 & 27,565 & 47 \\
\hline & Compromise & 597 & 1359 & 228 & 914 & 3623 & 4625 & 3432 & 76 & 27,560 & 47 \\
\hline \multirow{3}{*}{$\mathrm{OF} 3 / 4$} & MinOF3 & 4735 & 1612 & 315 & 6 & 29 & 0 & 3852 & 38 & 21,169 & 11 \\
\hline & MinOF4 & 2076 & 1985 & 257 & 208 & 3871 & 3913 & 2746 & 29 & 32,042 & 27 \\
\hline & Compromise & 2078 & 1969 & 236 & 201 & 3868 & 638 & 2753 & 29 & 32,021 & 27 \\
\hline
\end{tabular}

* Objective functions (OF): OF1: Annual costs (\$/year), OF2: Annual $\mathrm{CO}_{2, \mathrm{eq}}$ emissions (tn/year), OF3: Land use

$\left(\mathrm{km}^{2}\right)$, OF4: Social opposition (\%).

Figure 11 displays the ranges of Pareto-optimal power generation mixes throughout the different periods. The boxplots illustrate the lower and upper limits of the non-dominated solutions of power generation mix. The central red line in the whisker charts represents the median, while the bottom and top edges of the blue boxes indicate the 25th and 75th percentiles, respectively. The black whiskers cover the non-outliers that represent the most extreme data points. As an example, the lower limit of the coal technology suggests a solution with a lower carbon footprint but perhaps a higher discounted cost and vice versa. Nonetheless, a general trend can be observed across different periods. Initially, coal was the dominant energy contributor due to its existing capacity that is yet to be decommissioned and replaced. Furthermore, it can be seen that coal's share of power generation is reduced across the years due to the lower carbon emissions requirements. However, the rate of reduction is smoothened by the objectives for minimum land use and cost. Gas share sustains considerable share in the electricity mix throughout 2020 to 2025 (and even 2030, albeit the introduction of carbon taxes) to compensate for the reduction of coal, leading to the replacement of coal partly by gas (as an alternative cleaner fossil fuel with less land use and relatively lower environmental impact).

As far as renewables are concerned, solar PV exhibited the greatest increase throughout the first and second periods, as it occupies relatively less land, is socially acceptable, and amongst the cheapest RE technologies. Another RE technology that also witnessed a notable increase was geothermal throughout the three periods. On the other hand, hydro and biomass technologies' share in electricity production was supressed, since both require extensive amount of land and the former technology is also relatively not socially acceptable; however, hydro appears to increase its share during the last period, when the cost minimisation is the single objective accompanied by the carbon tax imposition policy. These factors prevented a greater penetration of RE technologies throughout 2020 and 2025. In addition, offshore wind and solar CSP comprised negligible levels across each period mainly due to their cost and relatively low annual construction limits.

Despite the slow phasing out of fossil fuels and increase in RE share, there was a lower weighted mean installed capacity for RE resources in 2030 compared to previous periods. This is because the single objective optimisation favoured a move towards gas technologies. Furthermore, the MO favoured the deployment of hydro from 2025 to 2030 highlighting the influence of minimisation of $\mathrm{CO}_{2, \mathrm{eq}}$ emissions and land use during the first two periods. 


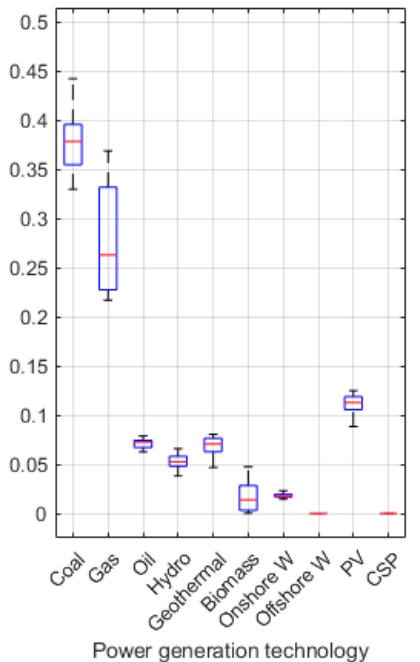

(a)

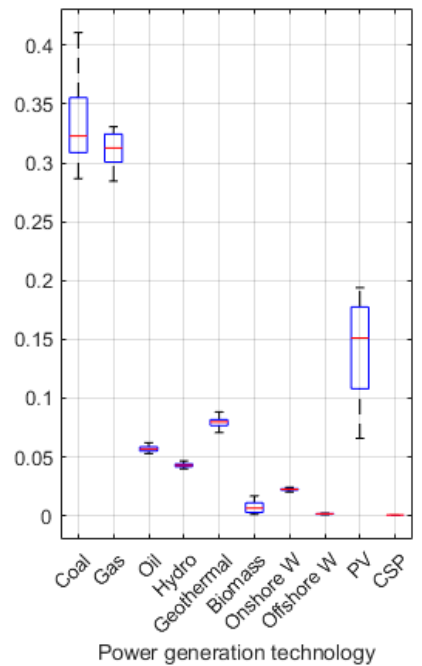

(b)

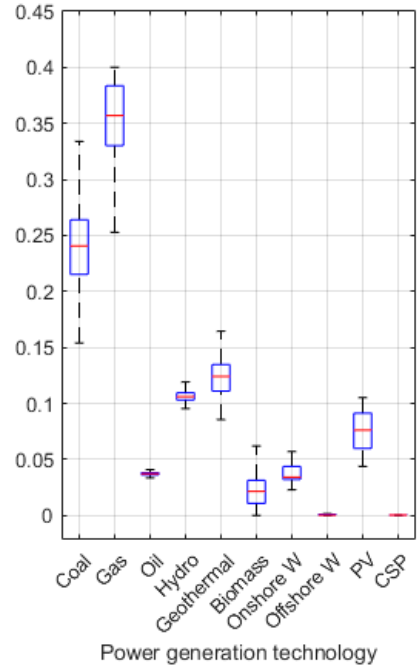

(c)

Figure 11. Power generation mixes of the Pareto-optimal solutions obtained during each period:

(a) 2020, (b) 2025, and (c) 2030.

The carbon emissions of the power sector across the planning horizon is shown in Figure 12a. Considering the annual increase in electricity demand, the absolute values of the $\mathrm{CO}_{2, \text { eq }}$ emissions do not allow a meaningful comparison throughout each period; therefore, a normalised approach was adopted. As a result, the carbon intensity across each period was measured and subsequently plotted in Figure 12b. It can be noticed that the carbon intensity of the power generation mix exhibited an overall decrease. However, this decrease was greater between 2025 and 2030 due to the inertia of the system, as well as due to the imposition of a carbon tax during the last period. Moreover, the introduction of carbon tax into the final period also affected the discounted cost, as shown in Figure 12c, demonstrating a steeper rise compared to the increase between 2020 and 2025.

As shown in Figure 12d, the land use remains roughly constant throughout the first two periods, presenting an increase during the last period of the optimisation, favouring the installation of land intensive technologies. Nonetheless, the social opposition witnessed a considerable decrease between 2020 and 2025, derived from the reduction of coal technologies and suppression of onshore wind and hydro power. Yet, the social opposition slightly increases between 2025 and 2030 since the reduction of coal was replaced with other less socially favoured technologies, including hydro. As shown in Figure 12f, the renewable share grows steadily throughout the planning horizon.

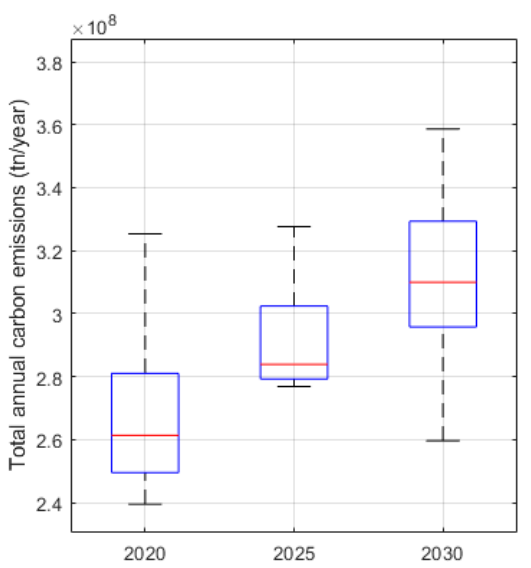

(a)

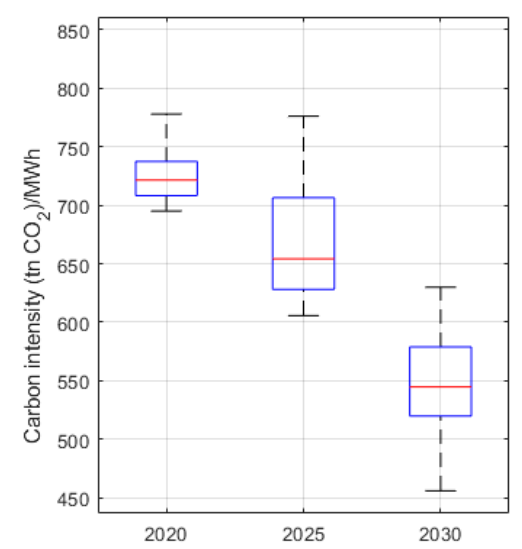

(b)

Figure 12. Cont. 


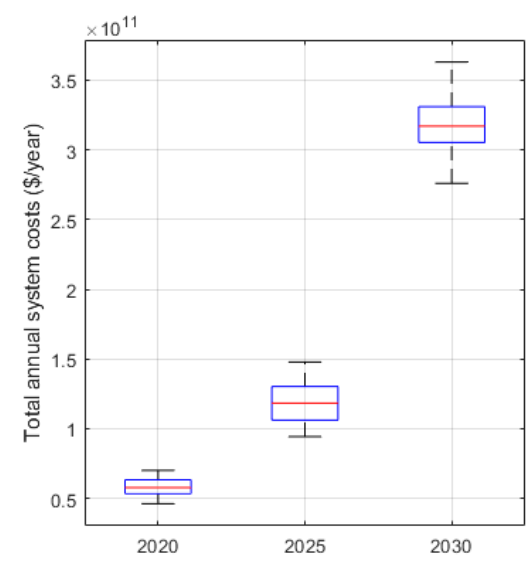

(c)

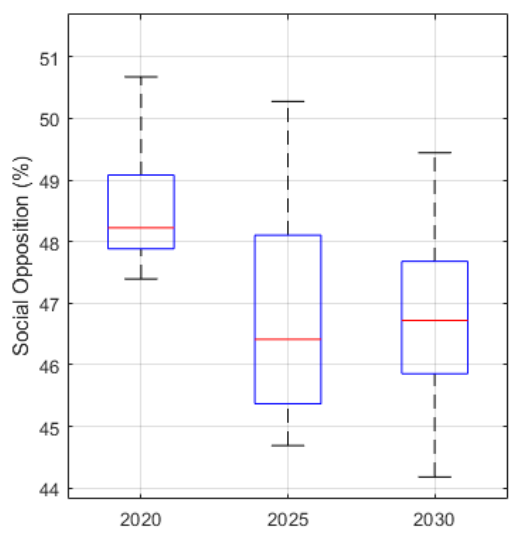

(e)

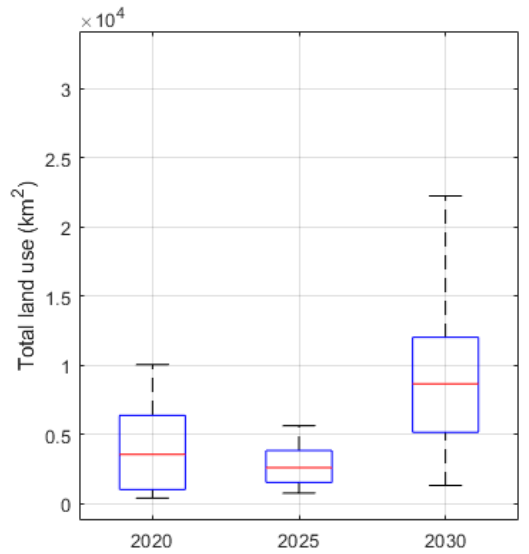

(d)

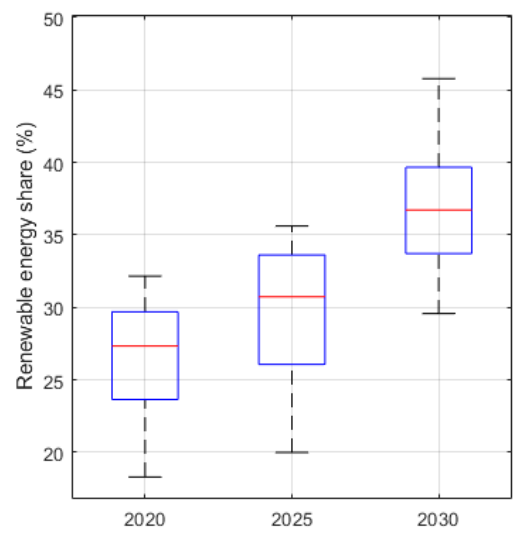

(f)

Figure 12. (a) Carbon emissions, (b) Carbon intensity, (c) Discounted costs, (d) Land use, (e) Social opposition, and (f) Renewable contribution of the Pareto-optimal solutions generated across each period.

\section{Conclusions}

This paper highlighted the importance of incorporating sustainability criteria into long-term power system planning by means of a MO approach. The developed MO model incorporates indicators, such as carbon emissions, land use, social opposition, jobs created, mortality rate, RE penetration, energy diversity, and import dependency. Before applying the MO model, several single-objective optimisations were carried out to investigate the impact of each objective on the power generation mix. It was deduced that least cost and land use scenarios favoured fossil fuel technologies, with the latter to a greater extent. On the other hand, the minimum carbon emissions scenario led to higher renewable energy contribution, along with more jobs created, as well as lower social opposition. To minimise social opposition due to adverse visual, noise, and social impact, hydro and onshore wind technologies were also phased out and replaced by other RE technologies. Despite the dissimilarities that were present amongst the scenarios, coal and gas technologies remained a significant part of the power generation mix.

The MO model employed a genetic algorithm (NSGA-II) in the first two periods, and, subsequently, a single-objective linear optimisation in the third period. Using the former algorithm allowed the optimisation per pair of objective functions, leading to the generation of multiple non-dominated solutions where trade-offs were present. The algorithm employed does not require the input of arbitrary weights, such as in the case of the weighted-sum approach. The normalisation of the objective functions into dimensionless units is also not required, which could pose a challenge in certain situations. 
Furthermore, the generation of multiple distinct solutions provides the decision-maker a degree of flexibility, in which they can select a solution based on their preferences. A trade-off analysis was performed deriving Pareto front candidates for each pair of objective functions towards assisting decision-makers investigate the trade-offs among objective functions and find acceptable solutions. To this aim, three non-dominated solutions, two extremes corresponding to the minimum values of the two objective functions, and a compromise value for each Pareto front were retrieved. It was observed that the values of the extreme solutions of the cost minimisation objective function remain the same across all Pareto fronts. Furthermore, lack of trade-offs was observed between the minimisation of $\mathrm{CO}_{2, \text { eq }}$ emissions with the social opposition, as well as between the total cost and land use objective functions, deriving similar results in their extreme and compromise solutions.

To this end, subsequent MOs involved annual cost and $\mathrm{CO}_{2, \text { eq }}$ emissions as objective functions during the first two periods and a linear constrained optimisation, during the final period, assuming the minimisation of costs as objective function with inputs the non-dominated solutions from the former period and an imposed carbon tax of $30 \$ / \mathrm{tnCO}_{2, \mathrm{eq}}$. This way the solution during the final optimisation period could be tailored towards the decision-maker's priority objective, while less computation effort reduced the complexity of the problem. This method can be generalised to implement multi-period MOs with varying objective functions through the different periods of the power systems expansion planning, according to the foreseen priorities of the stakeholders. The derived solutions were plotted in boxplots to demonstrate the upper and lower limits, along with a general trend of the power generation mixes throughout each period. Furthermore, insights regarding the carbon emissions, carbon intensity, discounted costs, land use, social opposition, and renewable contribution of the Pareto-optimal solutions were illustrated across each period.

The model developed could be a valuable tool for policy makers designing policies for long term energy system modelling and, specifically, for densely populated-and socially-influenced nations where land use and social opposition constraints are important to be taken into consideration together with the discounted total costs and carbon emissions.

Author Contributions: Conceptualization, T.A.S., A.I. and G.F.; formal analysis, T.A.S. and A.I.; investigation, T.A.S. and A.I.; methodology, T.A.S., A.I. and G.F.; software, T.A.S. and A.I.; visualization, T.A.S.; supervision, A.I. and G.F.; project administration, G.F.; writing-original draft, T.A.S.; writing-review and editing, A.I. and G.F. All authors have read and agreed to the published version of the manuscript.

Funding: This research received no external funding.

Conflicts of Interest: The authors declare no conflict of interest.

\section{Abbreviations}

$\begin{array}{ll}\text { CSP } & \text { Concentrated Solar-Thermal Power } \\ \text { GA } & \text { Genetic Algorithm } \\ \text { GHG } & \text { Greenhouse Gas } \\ \text { PCF } & \text { Pulverised Coal Fired } \\ \text { MO } & \text { Multi-objective Optimisation } \\ \text { MOEA } & \text { Multi-Objective Evolutionary Algorithm } \\ \text { NGCC } & \text { Natural Gas Combined Cycle } \\ \text { NSGA } & \text { Non-dominated Sorting Genetic Algorithm } \\ \text { OF } & \text { Objective Function } \\ \text { PV } & \text { Photovoltaic } \\ \text { RE } & \text { Renewable Energy }\end{array}$

\section{References}

1. International Energy Agency (IEA). Global Energy \& $\mathrm{CO}_{2}$ Status Report. The Latest Trends in Energy and Emissions in 2018. Available online: https://webstore.iea.org/global-energy-co2-status-report-2018 (accessed on 10 March 2020). 
2. Gielen, D.; Boshell, F.; Saygin, D.; Bazilian, M.D.; Wagner, N.; Gorini, R. The role of renewable energy in the global energy transformation. Energy Strat. Rev. 2019, 24, 38-50. [CrossRef]

3. UNFCCC Kyoto Protocol to the United Nations Framework Convention on Climate Change adopted at COP3 in Kyoto, Japan, on 11 December 1997. Available online: https://unfccc.int/resource/docs/convkp/kpeng.pdf (accessed on 10 February 2020).

4. UNFCCC. The Paris Agreement. Available online: https://unfccc.int/sites/default/files/english_paris_ agreement.pdf (accessed on 10 February 2020).

5. European Commission (EC) 2030 Energy Strategy. Available online: https://ec.europa.eu/clima/policies/ strategies/2030_en (accessed on 20 March 2020).

6. Li, Y.; Huang, G. Electric-power systems planning and greenhouse-gas emission management under uncertainty. Energy Convers. Manag. 2012, 57, 173-182. [CrossRef]

7. Cano, E.L.; Moguerza, J.M.; Alonso-Ayuso, A. A multi-stage stochastic optimization model for energy systems planning and risk management. Energy Build. 2016, 110, 49-56. [CrossRef]

8. Ioannou, A.; Fuzuli, G.; Brennan, F.; Yudha, S.W.; Angus, A. Multi-stage stochastic optimization framework for power generation system planning integrating hybrid uncertainty modelling. Energy Econ. 2019, 80, 760-776. [CrossRef]

9. Cormio, C.; Dicorato, M.; Minoia, A.; Trovato, M. A regional energy planning methodology including renewable energy sources and environmental constraints. Renew. Sustain. Energy Rev. 2003, 7, 99-130. [CrossRef]

10. Grafakos, S.; Flamos, A. Assessing low-carbon energy technologies against sustainability and resilience criteria: Results of a European experts survey. Int. J. Sustain. Energy 2017, 36, 502-516. [CrossRef]

11. Larsen, S.V.; Hansen, A.M.; Nielsen, H.N. The role of EIA and weak assessments of social impacts in conflicts over implementation of renewable energy policies. Energy Policy 2018, 115, 43-53. [CrossRef]

12. Al Garni, H.Z.; Kassem, A.; Awasthi, A.; Komljenovic, D.; Al-Haddad, K. A multicriteria decision making approach for evaluating renewable power generation sources in Saudi Arabia. Sustain. Energy Technol. Assess. 2016, 16, 137-150. [CrossRef]

13. Poggi, F.; Firmino, A.; Amado, M. Planning renewable energy in rural areas: Impacts on occupation and land use. Energy 2018, 155, 630-640. [CrossRef]

14. Özcan, E.; Erol, S. A multi-objective mixed integer linear programming model for energy resource allocation problem: The case of turkey. Gazi Univ. J. Sci. 2014, 27, 1157-1168.

15. Chang, K.-H. Multiobjective Optimization and Advanced Topics. In Design Theory and Methods Using $C A D / C A E$; Elsevier BV: Amsterdam, The Netherlands, 2015; pp. 325-406.

16. Tekiner, H.; Coit, D.W.; Felder, F.A. Multi-period multi-objective electricity generation expansion planning problem with Monte-Carlo simulation. Electr. Power Syst. Res. 2010, 80, 1394-1405. [CrossRef]

17. Cabello, J.M.; Luque, M.; Miguel, F.; Ruiz, A.B.; Ruiz, F.; García, F.M. A multiobjective interactive approach to determine the optimal electricity mix in Andalucía (Spain). TOP 2011, 22, 109-127. [CrossRef]

18. Liu, Y.; Li, H.; Chen, Y. Development of a single-level optimization model for energy planning-A case study of Shanxi, China. Math. Sci. Appl. 2017, 40007. [CrossRef]

19. Dorotić, H.; Pukšec, T.; Duić, N. Economical, environmental and exergetic multi-objective optimization of district heating systems on hourly level for a whole year. Appl. Energy 2019, 251, 113394. [CrossRef]

20. Promjiraprawat, K.; Limmeechokchai, B. Multi-objective and multi-criteria optimization for power generation expansion planning with CO2 mitigation in Thailand. Songklanakarin J. Sci. Technol. 2013, 35, 349-359.

21. Prebeg, P.; Gasparovic, G.; Krajačić, G.; Duić, N. Long-term energy planning of Croatian power system using multi-objective optimization with focus on renewable energy and integration of electric vehicles. Appl. Energy 2016, 184, 1493-1507. [CrossRef]

22. Mahbub, S.; Viesi, D.; Cattani, S.; Crema, L. An innovative multi-objective optimization approach for long-term energy planning. Appl. Energy 2017, 208, 1487-1504. [CrossRef]

23. Prina, M.G.; Cozzini, M.; Garegnani, G.; Manzolini, G.; Moser, D.; Oberegger, U.F.; Pernetti, R.; Vaccaro, R.; Sparber, W. Multi-objective optimization algorithm coupled to EnergyPLAN software: The EPLANopt model. Energy 2018, 149, 213-221. [CrossRef]

24. Trotter, P.A.; Cooper, N.J.; Wilson, P.R. A multi-criteria, long-term energy planning optimisation model with integrated on-grid and off-grid electrification - The case of Uganda. Appl. Energy 2019, 243, 288-312. [CrossRef] 
25. Ugranl1, F. Analysis of renewable generation's integration using multi-objective fashion for multistage distribution network expansion planning. Int. J. Electr. Power Energy Syst. 2019, 106, 301-310. [CrossRef]

26. Celli, G.; Pilo, F.; Pisano, G.; Soma, G.G. Distribution energy storage investment prioritization with a real coded multi-objective Genetic Algorithm. Electr. Power Syst. Res. 2018, 163, 154-163. [CrossRef]

27. Abdelkader, A.; Rabeh, A.; Ali, D.M.; Mohamed, J.; Abbassi, A.; Abbassi, R.; Dami, M.A.; Jemli, M. Multi-objective genetic algorithm based sizing optimization of a stand-alone wind/PV power supply system with enhanced battery/supercapacitor hybrid energy storage. Energy 2018, 163, 351-363. [CrossRef]

28. Saber, H.; Moeini-Aghtaie, M.; Ehsan, M. Developing a multi-objective framework for expansion planning studies of distributed energy storage systems (DESSs). Energy 2018, 157, 1079-1089. [CrossRef]

29. Cheung, B.C.; Carriveau, R.; Ting, D.S.-K. Multi-objective optimization of an underwater compressed air energy storage system using genetic algorithm. Energy 2014, 74, 396-404. [CrossRef]

30. Mytilinou, V.; Kolios, A. A multi-objective optimisation approach applied to offshore wind farm location selection. J. Ocean Eng. Mar. Energy 2017, 3, 265-284. [CrossRef]

31. Mytilinou, V.; Kolios, A. Techno-economic optimisation of offshore wind farms based on life cycle cost analysis on the UK. Renew. Energy 2019, 132, 439-454. [CrossRef]

32. Ghorbani, N.; Kasaeian, A.; Toopshekan, A.; Bahrami, L.; Maghami, A. Optimizing a hybrid wind-PV-battery system using GA-PSO and MOPSO for reducing cost and increasing reliability. Energy 2018, 154, 581-591. [CrossRef]

33. Tang, J.; Wang, D.; Wang, X.; Jia, H.; Wang, C.; Huang, R.; Yang, Z.; Fan, M. Study on day-ahead optimal economic operation of active distribution networks based on Kriging model assisted particle swarm optimization with constraint handling techniques. Appl. Energy 2017, 204, 143-162. [CrossRef]

34. Deb, K. Multi-objective Optimisation Using Evolutionary Algorithms: An Introduction. In Multi-objective Evolutionary Optimisation for Product Design and Manufacturing; Wang, L., Ng, A.H.C., Deb, K., Eds.; Springer: London, UK, 2011; pp. 3-34. ISBN 978-0-85729-652-8.

35. Konak, A.; Coit, D.W.; Smith, A.E. Multi-objective optimization using genetic algorithms: A tutorial. Reliab. Eng. Syst. Saf. 2006, 91, 992-1007. [CrossRef]

36. Deb, K. Multi-Objective Optimization Using Evolutionary Algorithms; John Wiley \& Sons: New York, NY, USA, 2001.

37. Onat, N.; Bayar, H. The sustainability indicators of power production systems. Renew. Sustain. Energy Rev. 2010, 14, 3108-3115. [CrossRef]

38. Kourkoumpas, D.-S.; Benekos, G.; Nikolopoulos, N.; Karellas, S.; Grammelis, P.; Kakaras, E. A review of key environmental and energy performance indicators for the case of renewable energy systems when integrated with storage solutions. Appl. Energy 2018, 231, 380-398. [CrossRef]

39. Colla, M.; Ioannou, A.; Falcone, G. Critical review of competitiveness indicators for energy projects. Renew. Sustain. Energy Rev. 2020, 125, 109794. [CrossRef]

40. Shaaban, M.; Scheffran, J.; Böhner, J.; ElSobki, M.S. Sustainability Assessment of Electricity Generation Technologies in Egypt Using Multi-Criteria Decision Analysis. Energies 2018, 11, 1117. [CrossRef]

41. Malekpoor, H.; Chalvatzis, K.; Mishra, N.; Mehlawat, M.K.; Zafirakis, D.; Song, M. Integrated grey relational analysis and multi objective grey linear programming for sustainable electricity generation planning. Ann. Oper. Res. 2017, 269, 475-503. [CrossRef]

42. Grafakos, S.; Enseñado, E.M.; Flamos, A. Developing an integrated sustainability and resilience framework of indicators for the assessment of low-carbon energy technologies at the local level. Int. J. Sustain. Energy 2016, 36, 945-971. [CrossRef]

43. Deb, K.; Pratap, A.; Agarwal, S.; Meyarivan, T. A fast and elitist multiobjective genetic algorithm: NSGA-II. IEEE Trans. Evol. Comput. 2002, 6, 182-197. [CrossRef]

44. MathWorks Documentation R2020a Multiobjective Genetic Algorithm Options. Available online: https: //uk.mathworks.com/help/gads/gamultiobj-options-effects.html (accessed on 12 April 2020).

45. Jordan, D.; Kurtz, S.R.; VanSant, K.; Newmiller, J. Compendium of photovoltaic degradation rates. Prog. Photovolt. Res. Appl. 2016, 24, 978-989. [CrossRef]

46. Weather Altlas Monthly Weather Forecast and Climate Jakarta, Indonesia. Available online: https://www. weather-atlas.com/en/indonesia/jakarta-climate (accessed on 20 March 2020).

47. Jordan, D.; Kurtz, S.R. Photovoltaic Degradation Rates-an Analytical Review. Prog. Photovolt. Res. Appl. 2011, 21, 12-29. [CrossRef] 
48. Pambudi, N.A. Geothermal power generation in Indonesia, a country within the ring of fire: Current status, future development and policy. Renew. Sustain. Energy Rev. 2018, 81, 2893-2901. [CrossRef]

49. Dones, R.; Heck, T.; Hirschberg, S. Greenhouse Gas Emissions from Energy Systems, Comparison and Overview. Encycl. Energy 2004, 77-95. [CrossRef]

50. IRENA. The Power to Change: Solar and Wind Cost Reduction Potential to 2025. Available online: https://www.irena.org/-/media/Files/IRENA/Agency/Publication/2016/IRENA_Power_to_Change_ 2016.pdf (accessed on 1 April 2020).

51. Thangavelu, S.R.; Khambadkone, A.; Karimi, I.A. Long-term optimal energy mix planning towards high energy security and low GHG emission. Appl. Energy 2015, 154, 959-969. [CrossRef]

52. China Light \& Power (CLP). Generating Capacity \& Reserve Margin. Available online: https://www.clpgroup.com/en/Media-Resources-site/Current\%20Releases\%20Documents/20131210/ FactSheet2_Generating_Capacity_Reserve_Margin_eng.pdf (accessed on 20 March 2020).

53. International Electrotechnical Commission (IEC). Efficient Electrical Energy Transmission and Distribution; IEC: Geneva, Switzerland, 2007.

54. Devine-Wright, P. Reconsidering public attitudes and public acceptance of renewable energy technologies: A critical review. Architecture 2007, 1-15.

55. Haddad, B.; Liazid, A.; Ferreira, P.; Haddah, B. A multi-criteria approach to rank renewables for the Algerian electricity system. Renew. Energy 2017, 107, 462-472. [CrossRef]

56. Eurostat Oil and Petroleum Products-A Statistical Overview-Statistics Explained. Available online: https://ec.europa.eu/eurostat/statistics-explained/index.php?title=Oil_and_petroleum_products_-_ a_statistical_overview\&oldid=315177\#Oil_imports_dependency (accessed on 12 August 2019).

57. Asian Development Bank. Indonesia Energy Sector, Assessment, Strategy, and Road Map. July 2016. Available online: https://www.adb.org/sites/default/files/institutional-document/189713/ino-energy-asr.pdf (accessed on 2 April 2020).

58. Worldometers Indonesia Population (2019)—Worldometers. Available online: https://www.worldometers. info/world-population/indonesia-population/ (accessed on 10 August 2019).

59. CIA East Asia/Southeast Asia: Indonesia-The World Factbook-Central Intelligence Agency. Available online: https://www.cia.gov/library/publications/the-world-factbook/geos/id.html (accessed on 10 August 2019).

60. BP Country Insight-Indonesia. Available online: https://www.bp.com/en/global/corporate/energyeconomics/statistical-review-of-world-energy/country-and-regional-insights/indonesia.html (accessed on 11 August 2019).

61. McNeil, M.A.; Karali, N.; Letschert, V. Forecasting Indonesia's electricity load through 2030 and peak demand reductions from appliance and lighting efficiency. Energy Sustain. Dev. 2019, 49, 65-77. [CrossRef]

62. Ministry of Energy and Mineral Resources of Indonesia (ESDM). Electricity Supply Business Plan (Rencana Usaha Penyediaan Tenaga Listrik) 2018-2027; ESDM: Jakarta, Indonesia, 2018.

63. Dutu, R. Challenges and policies in Indonesia's energy sector. Energy Policy 2016, 98, 513-519. [CrossRef]

64. Nasruddin, N.; Alhamid, M.I.; Daud, Y.; Surachman, A.; Sugiyono, A.; Aditya, H.; Mahlia, T.M.I. Potential of geothermal energy for electricity generation in Indonesia: A review. Renew. Sustain. Energy Rev. 2016, 53, 733-740. [CrossRef]

65. Darma, S. Indonesia: Vast geothermal potential, modest but growing exploitation. Geotherm. Power Gener. 2016, 609-643.

66. IRENA, Renewable Energy Prospects: Indonesia, a REmap analysis, International Renewable Energy Agency (IRENA). Available online: http://www.irena.org/remap (accessed on 10 February 2020).

67. Fungenzi, T. Biomass as An Opportunity to Solve Indonesia's Energy Challenge. 2015. Available online: https://www.researchgate.net/publication/280075489_Biomass_as_an_opportunity_to_ solve_Indonesia|T1 textquoterights_energy_challenge (accessed on 14 January 2020).

68. Erinofiardi; Gokhale, P.; Date, A.; Akbarzadeh, A.; Bismantolo, P.; Suryono, A.F.; Mainil, A.K.; Nuramal, A. A Review on Micro Hydropower in Indonesia. Energy Procedia 2017, 110, 316-321. [CrossRef]

69. PWC. Power in Indonesia, 5th ed. Available online: https://www.pwc.com/id/en/energy-utilities-mining/ assets/power/power-guide-2017.pdf (accessed on 3 January 2020). 
70. IEA/IRENA Solar Feed-In Tariff of Indonesia (2016). Available online: https://www.iea.org/policies/6335solar-feed-in-tariff-of-indonesia-2016?sector=Electricity\&type=Fiscal\%2Ffinancial\%20incentives (accessed on 7 March 2020).

71. Dang, M.-Q. Solar Energy Potential in Indonesia. 2017. Available online: https://www.researchgate.net/ publication/324840601_SOLAR_ENERGY_POTENTIAL_IN_INDONESIA (accessed on 25 February 2020).

72. Martosaputro, S.; Murti, N. Blowing the Wind Energy in Indonesia. Energy Procedia 2014, 47, $273-282$. [CrossRef]

73. Victor, P. Indonesia's Wind Energy Potential. Available online: https://theaseanpost.com/article/indonesiaswind-energy-potential (accessed on 18 August 2019).

74. UNCCD. IRENA Energy and Land Use. Global Land Outlook Working Paper. Available online: https://www.researchgate.net/publication/319715882_ENERGY_AND_LAND_USE_-_GLOBAL_ LAND_OUTLOOK_WORKING_PAPER (accessed on 1 March 2020).

75. Wei, M.; Patadia, S.; Kammen, D.M. Putting renewables and energy efficiency to work: How many jobs can the clean energy industry generate in the US? Energy Policy 2010, 38, 919-931. [CrossRef]

76. Statista Mortality Rate Globally by Energy Source 2018. Available online: https://www.statista.com/statistics/ 494425/death-rate-worldwide-by-energy-source/ (accessed on 10 August 2019).

77. National Renewable Energy Laboratory (NREL) 2018 ATB Cost and Performance Summary. Available online: https://atb.nrel.gov/electricity/2018/summary.html (accessed on 12 August 2019).

78. Indexmundi Indonesian Liquified Natural Gas-Monthly Price-Commodity Prices—Price Charts, Data, and News-IndexMundi. Available online: https://www.indexmundi.com/commodities/?commodity= indonesian-liquified-natural-gas\&months $=60$ (accessed on 11 August 2019).

79. Knoema.com. Indonesia Diesel Price, 1960-2018-knoema.com. Available online: https://knoema.com/atlas/ Indonesia/Diesel-price (accessed on 10 August 2019).

80. Tradingeconomics.com. Trading Economics Application Programming Interface (API). Available online: https://tradingeconomics.com/commodity/coa (accessed on 11 August 2019).

81. Cernea, M. Hydropower Dams and Social Impacts: A Sociological Perspective. Available online: http://documents.worldbank.org/curated/en/446311468761673943/Hydropower-dams-and-socialimpacts-a-sociological-perspective (accessed on 25 January 2020).

(C) 2020 by the authors. Licensee MDPI, Basel, Switzerland. This article is an open access article distributed under the terms and conditions of the Creative Commons Attribution (CC BY) license (http://creativecommons.org/licenses/by/4.0/). 